\title{
La cuestión agraria y el cobre en la provincia de El Loa (1929/30 - 2006/07). Andes centro-sur, norte de Chile
}

\section{The agrarian question and the copper in the Province of El Loa (1929/30 - 2006/07). Andes south-central, northern Chile}

\author{
Matías Calderón ${ }^{1,2}$ https://orcid.org/0000-0002-0802-7641 \\ Manuel Prieto $^{3}$ https://orcid.org/0000-0003-4262-3786 \\ ${ }^{1}$ Programa de Doctorado en Antropología, Instituto de Arqueología y Antropología, \\ Universidad Católica del Norte, San Pedro de Atacama, CHILE. \\ Email: mcalderonseguel@gmail.com. \\ ${ }^{2}$ Grupo de Investigación en Ciencias Sociales y Economía (GICSEC), Santiago, CHILE. \\ ${ }^{3}$ Departamento de Ciencias Históricas y Geográficas, Universidad de Tarapacá, Arica, CHILE. \\ Email: mprieto@academicos.uta.cl.
}

\begin{abstract}
Resumen
La provincia de El Loa, habitada históricamente por población andina dedicada a actividades agrícolas, pastoriles y de intercambio, ha ocupado un lugar estratégico en la expansión del extractivismo cuprífero chileno y su inserción internacional. Ahí se emplaza Chuquicamata, la que fuera durante parte importante del siglo XX la mina de cobre más grande del mundo. Para avanzar en la comprensión de las transformaciones territoriales que produce esta actividad, efectuamos un análisis histórico-estructural de la agricultura de la provincia entre 1929/30 y 2006/07. Caracterizamos analíticamente las transformaciones agrarias de la zona relacionando su desenvolvimiento con la expansión de la gran minería cuprífera. Teóricamente, nos posicionamos desde el paradigma de la cuestión agraria, reproblematizado a partir de los estudios sobre el extractivismo. En términos metodológicos, usamos estadísticas descriptivas de censos agropecuarios para caracterizar la estructura agraria, y fuentes históricas y secundarias para comprender sus conexiones con la explotación cuprífera.
\end{abstract}

Palabras clave: extractivismo, agricultura, minería, clases sociales, desierto de Atacama.

\begin{abstract}
The Province of El Loa, historically inhabited by the Andean population dedicated to agriculture, herding and exchange activities, has occupied a strategic place in the expansion of Chilean copper industry and its international insertion. Here is located Chuquicamata, the largest copper mine in the world by an important part of the 20 th century. To advance in the understanding of the territory that produces this activity, we carry out a historical-structural analysis of the agriculture practiced in the province between 1929/30 and 2006/07. We characterize analytically the agrarian transformations of the area relating their development with the expansion of the great copper mining. Theoretically, we position ourselves from the paradigm of the agrarian question, which we re-problematize by linking it with the studies on extractivism. Methodologically we use descriptive statistics of agricultural censuses for the characterization of the agrarian structure, and historical and secondary sources that allow us to understand their connections with the copper exploitation.
\end{abstract}

Keywords: extractivism, agriculture, mining, social classes, Atacama Desert.

Recibido: 17 enero 2019. Aceptado: 11 noviembre 2019 


\section{Introducción}

Durante los siglos XX y comienzos del XXI, las ruralidades latinoamericanas han experimentado grandes transformaciones, las que de modo más o menos rápido han establecido nuevas formas de vida en las poblaciones locales (Bengoa, 2003; Kay, 2009). Históricamente, como también durante el ciclo neoliberal de expansión capitalista (desde la década del ochenta), una causa central de ello corresponde a la inserción latinoamericana al mercado global y su posición en la división internacional del trabajo. Así, es un área periférica de economías dependientes, la mayoría, extractoras y exportadoras de materias primas con bajo procesamiento y en amplia escala, condición que se remonta al siglo XVI, cuando el continente se inserta como colonia en el capitalismo mundial emergente (Wallerstein, 2003; Marini, 2015).

La mayoría de los espacios involucrados en el desarrollo de operaciones extractivas corresponden a áreas rurales habitadas por poblaciones campesinas y asalariadas, muchas de ellas de base indígena. Por acción de distintas actividades -mineras, hidrocarburos, monocultivos frutícolas y forestales, hidroeléctricas, entre otras- se han constatado diversos cambios y conflictos socioambientales (Gudynas, 2013).

En Chile, la industria cuprífera ha sido la actividad extractiva preponderante durante todo el siglo XX hasta la actualidad. Sus exportaciones, pasando por distintos ciclos de auge y ralentización, se incrementaron desde 322 millones de dólares FOB en 1960 (68\% del total exportado) a 28.091 millones de dólares FOB en 2016 (46\% del total exportado) (Banco Central de Chile, s/f). ${ }^{1}$ Así, Chile se constituyó en el principal productor mundial de cobre. En efecto, la producción de cobre de mina de Chile aumentó desde 363000 toneladas métricas en 1950 (14\% del total global) a 5764000 toneladas métricas el 2015 (30\% del total mundial) (Comisión Chilena del Cobre, s.f.).

1 La reducción porcentual se debe al surgimiento de otros rubros extractivos, no obstante, el cobre se mantiene en el primer lugar.
La provincia de El Loa (región de Antofagasta), ubicada en el norte de Chile, ha jugado un papel gravitante en la expansión cuprífera. En 1915, cerca del entonces pueblo de Calama, inició operaciones Chuquicamata. Esta mina, de capitales estadounidenses hasta su nacionalización en 1971, ha protagonizado la extracción de cobre nacional y global. Durante prácticamente todo el siglo XX, ha sido el principal yacimiento cuprífero del país y del mundo (Millán, 2006). La producción de cobre en esta provincia ${ }^{2}$ ascendió desde 231000 toneladas métricas en 1960 (43\% del total nacional) a 1010000 toneladas métricas en 2015 (18\% del total del país) ${ }^{3}$ (Cochilco, s.f.).

Por su parte, la provincia de El Loa ha sido habitada desde tiempos prehispánicos por población andina dedicada principalmente a actividades agropecuarias y de intercambio, y en menor medida, a la pequeña minería; dinámicas inmersas en complejas redes económicas, políticas y culturales con otros espacios de los Andes (Aldunate et al., 1986; Pourrut y Núñez, 1995; Castro y Martínez, 1996, entre otros). Con la instauración de la Colonia y en adelante, existen diversas transformaciones en los modos de vida tradicional. Sin embargo, desde la apertura de Chuquicamata, la velocidad y cualidad de los cambios adquieren nuevas fisonomías.

El área no ha estado exenta de investigaciones sobre dinámicas territoriales relativas a la expansión cuprífera, de las cuales destacamos dos grandes ámbitos. Por una parte, estudios sobre la minería de cobre, conflictos territoriales y recursos naturales, enfatizando las dinámicas de despojo (Aldunate, 1985; Cuadra, 2000; Yáñez y Molina, 2008, 2011; Prieto, 2015) como también sus conflictos y subjetividades (Carrasco y Fernández, 2009; Molina, 2012; Bolados, 2014; Carrasco, 2014, 2016; Morales y Azócar, 2015; Prieto, 2016a, 2016b). Por otra parte, aproximaciones que ahondan en procesos institucionales, identidades y relaciones sociales, en

2 Fue la única gran mina de cobre de la zona hasta fines del siglo XX e inicios del XXI, cuando inician funcionamiento Radomiro Tomic (estatal), El Abra (privada/ estatal) y Ministro Hales (estatal).

3 La baja porcentual se debe a la apertura de grandes yacimientos cupríferos en el norte y centro del país, pero no por una merma en la extracción en este territorio. 
torno a la presencia estatal y la expansión cuprífera (Gundermann 2007; Imilan, 2007; Gundermann, 2013; Gundermann et al., 2018). Un acercamiento que aborda distintas dimensiones del fenómeno en Castro y Martínez (1996).

Estas investigaciones han generado avances en el conocimiento del fenómeno. Sin embargo, escasean análisis actualizados sobre las reconfiguraciones de las estructuras económicas de las poblaciones indígenas, especialmente de actividades tradicionales como la agricultura. De las indagaciones que sí problematizan esto, la mayoría privilegió escalas de análisis menores a la provincial. De los estudios que tienen una mirada provincial o similar (Bähr, 1985; Consecol, 1988; Fundación Chile, 1993; Gundermann, 1998), los más recientes corresponden a la década del noventa. Respecto de los estudios que abordan niveles de análisis menores a la provincia, en la cuenca del río Loa solo uno es posterior al ańo 2000 (Hernández, 1974; Hernández, Poblete y Quiroz, 1975; Cavieres, 1985; Martínez, 1985; Villagrán y Castro, 1997; González, 1999; Ilustre Municipalidad de Calama, 2013). Igualmente, en la cuenca del salar de Atacama solo una publicación es posterior al 2000 (Aranda, 1961; Folla, 1989; Pourrut y Núñez, 1995; Sepúlveda, Molina, DelgadoSerrano y Guerrero, 2015).

Considerando el estado del arte, en este artículo respondemos dos preguntas complementarias: i) ¿Cuál es la dinámica de la estructura agraria de la provincia de El Loa entre 1929/30 y 2006/07?, y ii) ¿Qué conexiones existen entre la expansión cuprífera y las transformaciones de la estructura agraria provincial en el período indagado?

Nuestras respuestas a estas preguntas contribuyen al conocimiento del área en dos sentidos. Primero, efectuamos una interpretación actual de la dinámica agraria provincial, poniendo énfasis en las conexiones entre la expansión de la gran minería del cobre y las reconfiguraciones de la actividad. Segundo, utilizamos como fuente principal de información los censos agropecuarios; material de gran potencial, pero subestudiado a la fecha. Ello otorga una base y análisis cuantitativo sobre la cuestión agraria sincrónica y diacrónicamente, lo que permitirá enriquecer futuras investigaciones cualitativas. Desde una perspectiva más amplia, como se verá, aportamos al poner en conexión dos campos de investigación comúnmente indagados por separado, estos son los estudios sobre el extractivismo y los referentes a la cuestión agraria.

Como se desprende de las preguntas, seguimos un acercamiento estructural de la actividad agraria, el cual es contextualizado históricamente para comprender su dinámica. Tanto por la escala de análisis como por las fuentes de información (estadísticas e históricas secundarias), los resultados privilegian los aspectos generales de la provincia, profundizando excepcionalmente en casos de menor nivel. Para aquella antropología que prioriza los estudios de localidades y la etnografía (ver crítica de Llobera, 1999), este artículo puede incomodar. Sin embargo, creemos necesario construir una disciplina cuyas corrientes dominantes no hegemonicen todas sus posibilidades. Tan valiosos como los estudios etnográficos que abordan prácticas y subjetividades, son perspectivas como la propuesta que buscan mirar otros aspectos de lo social, por ejemplo, sus estructuras, usando otras escalas y metodologías.

El escrito se organiza como sigue: luego de la introducción, presentamos la discusión teórica sobre extractivismo y cuestión agraria, sigue la exposición de la metodología, luego la información básica del área de estudio; a continuación describimos aspectos básicos de la cuestión agraria anterior a la llegada de la industria cuprífera, proseguimos describiendo algunos antecedentes de dinámicas territoriales importantes para situar la cuestión agraria durante los siglos XX y XXI, continuamos con el análisis histórico-estructural de la cuestión agraria durante el mismo período; concluimos con algunas reflexiones finales.

\section{Extractivismo y cuestión agraria}

\section{Sobre el extractivismo}

Entendemos el extractivismo como la actividad económica de extracción y exportación de recursos naturales en amplia escala y con bajo procesamiento. Este fenómeno forma parte de la historia latinoamericana desde el período colonial (Machado, 2015). Esto no ha sido azaroso o un problema endógeno, 
sino que da cuenta del modo dominante de inserción y participación de Latinoamérica en el mercado mundial; expresión de su posición dependiente en la división internacional del trabajo (Marini, 2015), como parte de la periferia del capitalismo global (Wallerstein, 2003).

Estudiar el extractivismo cuprífero en la provincia de El Loa implica analizar el desarrollo capitalista en este territorio y los cambios que se producen en las poblaciones que lo han habitado desde larga data. En coordenadas antropológicas, nos situamos dentro del enfoque del sistema-mundo (Wolf, 2000). A grandes rasgos, se plantea que toda población o comunidad está conectada a la totalidad del capital, cumpliendo un rol en su reproducción; por tanto, no es posible pretender la existencia de poblaciones aisladas de las dinámicas capitalistas. El interés central está en explicar los cambios producidos en sus formas de vida por la penetración capitalista (estructuras, relaciones y lógicas), dar cuenta de las formas y ritmos de inserción de los niveles micro con los más amplios del sistema; a la vez, indagar en cómo las grandes tendencias del capitalismo adquieren expresiones concretas a escala local.

Volviendo al extractivismo, es relevante señalar que conceptualmente como campo de investigación, ha ganado fuerza desde la década del noventa, y por lo general, se ha utilizado para estudiar las dinámicas de su agudización y conflictos desde la década del ochenta. ${ }^{4}$ Sin embargo, la discusión teórica en América Latina no ha tenido la misma profusión. Predominan los acercamientos empíricos -descriptivos y comprensivos-, pero no una reflexión teórica sobre sus fundamentos (para algunas excepciones ver $\mathrm{Gu}$ dynas, 2013; Machado, 2015; Svampa, 2019).

Se ha privilegiado el análisis de actividades de extracción específicas, sus expresiones, conflictos y resistencias en territorios concretos, abordando diversas dimensiones (políticas, culturales y en menor medida, económicas). Existe una amplia literatura sobre estas temáticas, entre las que resaltamos las de

4 Especialmente respecto a la implementación de las políticas neoliberales (liberalización de mercados, privatización, desregulación y pérdida de protagonismo estatal en materia económica). interés para nuestro problema. Destacan las indagaciones sobre conflictos socioambientales que tienen como protagonistas a pueblos indígenas, comunidades locales, comunidades rurales, entre otros actores (Alimonda, 2011; Bebbington, 2012; Bebbington y Bury, 2013; Delgado, 2013; Göbel y Ulloa, 2014); también están las investigaciones que profundizan los conflictos por el agua (Arroyo y Boelens, 2013; Perreault, 2014; Yacoub, Duarte y Boelens, 2015); y las pesquisas que abordan las transformaciones en los modos de vida rurales (Bebbington, 2007).

Estas perspectivas, al analizar las manifestaciones territoriales de las relaciones de dependencia y expansión capitalista, abordan dimensiones históricamente minimizadas, como son los conflictos socioambientales, la diversidad de actores que participan, y las distintas identidades e imaginarios desplegados en la defensa de sus territorios. Los enfoques de la teoría de la dependencia (y sus variantes), que dominaron los estudios críticos hasta fines de la década del setenta e inicios de los ochenta, privilegiaron otros ángulos, como los niveles macrosociales (nacionales o continentales) con una mirada de economía política en la que el conflicto se trató en torno a las clases sociales (Acosta, 2016).

Las indagaciones sobre el extractivismo abrieron nuevas dimensiones y escalas de investigación. Sin embargo, la emergencia de estas aproximaciones fue en desmedro de los análisis de clases. Reconocen una serie de procesos, actores y conflictos que son propios del desarrollo extractivo, pero sin clases sociales en la escena, o sin profundizar en su conceptualización y expresión (ver algunas excepciones en Marston y Perreault, 2016; Veltmeyer, 2018).

\section{La cuestión agraria}

El análisis marxista de clases en el agro se conoce como el paradigma de la cuestión agraria. Destacan estudios sobre las contradicciones estructurales de la expansión capitalista en el agro, el rol de la agricultura en la constitución del capitalismo y la industria, las transformaciones y luchas de clases agrarias, la situación del campesinado y su articulación con los mercados, y el rol revolucionario del campesinado (Fernandes, 2014; Levien, Watts y Hairong 2018). De acuerdo a las características del caso de estudio, 
nos centramos en la estructura de clases agraria, la situación económica del campesinado y su articulación con los mercados.

\section{Sobre las clases sociales}

Dentro del marxismo, los principales debates sobre clases sociales han girado en torno a la preponderancia de los aspectos económicos estructurales o de los históricos, políticos y culturales. Siguiendo a Pérez (2008), entendemos que estos ámbitos son ángulos y temporalidades diferenciadas del mismo proceso, partes conectadas de una totalidad. Como señalara Marx (2003), "los hombres hacen su propia historia, pero no la hacen a su libre arbitrio, bajo circunstancias elegidas por ellos mismos, sino bajo aquellas circunstancias con que se encuentran directamente, que existen y les han sido legadas por el pasado" (p. 10).

Siguiendo a Marx (1959a), las clases sociales se forman a partir de relaciones de propiedad sobre los medios de producción y respecto del control de la fuerza de trabajo. Estas relaciones implican criterios de propiedad y distribución de las mercancías producidas. Siempre que existan propietarios y no propietarios de los medios de producción, esta distribución comprende apropiación desigual en beneficio de los dueños de los medios de producción en desmedro de los productores directos. Generalizando, reconoce tres grandes clases dentro del capitalismo: capitalistas, terratenientes y proletarios. Sin embargo, a nivel concreto, identifica una diversidad de clases (ver p.e., Marx, 2003). Entonces, las clases agropecuarias se configuran en el control de la tierra y otros medios de producción, y la forma de uso de la fuerza de trabajo, fundamentalmente, el rol del trabajo doméstico y la compra o venta de fuerza de trabajo externa a la familia. A partir de estos criterios, como se verá, se identifican distintas expresiones de campesinos, capitalistas agrarios, terratenientes, asalariados, entre otros.

Este artículo se focaliza en un análisis estructural de clases, por lo tanto, no nos extenderemos definiendo mayormente la dimensión de las experiencias. No obstante, la abordamos a través de la historización de la dinámica estructural, pero no es su objetivo ni existe el espacio- para profundizar en lo políticocultural.

\section{Marxismo clásico y campesinado}

Marx (1999) aborda cómo la expansión capitalista, al insertarse en espacios que están fuera de su órbita, impulsa la acumulación originaria de capital, según la cual por distintos mecanismos se produce el despojo de los medios de producción de los productores directos. ${ }^{5}$ Así, en la ruralidad, se constituye la propiedad capitalista de los medios productivos y trabajadores sin ellos (o que los poseen parcialmente), para que se vean obligados a vender su fuerza de trabajo. El campesinado ha sido uno de los principales afectados mediante la usurpación de sus bienes comunes, la expulsión física de la población y la destrucción de la industria doméstica rural. Es un proceso que opera de forma disímil espacial y temporalmente; en consecuencia, no existe una rápida y absoluta desaparición del campesinado. Con todo, la tendencia a largo plazo apuntaría al debilitamiento y descomposición de este. A los mecanismos existentes durante la acumulación originaria, se ańade la competencia de los productores agrícolas a gran escala (fijando precios y exigiendo inversiones), el empobrecimiento progresivo de la tierra campesina (por la dificultad de inversiones), la usura (para compra de tierras o insumos) y el sistema de impuestos (reduce su base económica) (Marx, 1959b).

El proceso de debilitamiento del campesinado se expresa en su diferenciación e incluso transformación en otras clases sociales. Engels (s.f.) da cuenta de cómo el "campesino medio" (trabaja su predio con la propia familia, sin contratar ni vender fuerza de trabajo) se transforma gradualmente e incluso va desapareciendo. Se forma una mayoría de "campesinos pobres" (venden parcialmente su fuerza de trabajo) y una minoría de "campesinos ricos" (contratan ocasionalmente a trabajadores). Con este proceso llevado a su límite, surgen nuevas clases como el asalariado rural y el capitalista agrario. Sin embargo, los distintos ritmos y expresiones de la expansión capitalista forman cuadros heterogéneos.

Lenin (1981) señala que la descomposición del campesino medio implica un proceso de "descampesinización" que da forma a nuevas clases agrarias:

5 Es fundamental el rol del Estado, tanto con sus fuerzas coercitivas como con base en la legalidad que sustenta el despojo. 
la burguesía (principalmente pequeña) y el proletariado. No obstante, en los países capitalistas se pueden dar distintas combinaciones. Reconoce la presencia de múltiples clases, como campesinos medios, campesinos acomodados (contratan fuerza de trabajo), campesinos pobres (venden fuerza de trabajo), pequeña burguesía agraria, gran capital agrario, terratenientes, proletarios con tierra de cultivo y asalariados plenos.

Kautsky (1981) propone algunos elementos que complejizan las formas que puede adquirir la proletarización campesina, de las cuales destacamos dos aspectos. Primero, la venta de fuerza de trabajo no es siempre dentro del sector agrario. En la ruralidad se instalan ciertas industrias que contratan fuerza de trabajo rural y desarrollan infraestructura, mercados y crecimiento urbano, destacando la minería. Segundo, la proletarización puede darse mediante migraciones temporales con movilidad dentro del propio país y fuera de este.

\section{Campesinado y cuestión agraria latinoamericana}

Mariátegui (2008) es uno de los que inaugura el análisis marxista agrario en Latinoamérica. Estableció que la pobreza y exclusión del campesinado indígena peruano se debe a la expropiación de sus tierras durante la Colonia, la formación de latifundios que funcionan sobre la base de la servidumbre y la dependencia del país respecto al mercado internacional. Sin embargo, el auge de esta problemática se produjo durante la década del setenta hasta inicio de la del ochenta (Kay, 2015). Luego, los estudios sobre la cuestión agraria perdieron fuerza. El debate quedó trunco, ya que el fenómeno fue ignorado. A medida que el neoliberalismo iba adquiriendo hegemonía, el análisis de clases perdió presencia en los estudios rurales (Kay, 2009).

Del período de auge, destaca el debate entre "campesinistas" y "descampesinistas" (Kay, 2015). O el campesinado tendía a fortalecerse y expandirse debido a las peculiaridades del capitalismo latinoamericano o, por el contrario, lo que se esperaba era su pronta desaparición. Adicionalmente, se propuso la conformación de un campesinado que oscilaba entre su debilitamiento y reforzamiento a medida que entraba o salía del mercado de trabajo. Otros enfa- tizaron en la diversidad de procesos, con dinámicas simultáneas y de distinta intensidad de campesinización y descampesinización.

Durante el período neoliberal emergieron otras dimensiones de estudio bajo el enfoque de la "nueva ruralidad" (Kay, 2009). De ellas relevamos los empleos rurales no agrícolas, el trabajo femenino, las dinámicas urbano-rurales y las movilidades nacionales e internacionales.

La cuestión agraria, luego de la crisis del neoliberalismo, vuelve a tener cierta presencia. Mantiene los enfoques clásicos y es también enriquecida con otras aproximaciones (Levien et al., 2018). Nuestro aporte apunta a indagar en el rol del capital extractivo minero como articulador de la cuestión agraria y del devenir campesino en determinados territorios donde predomina este capital. Este aspecto ha sido prácticamente ignorado. Algunas excepciones se pueden encontrar en estudios en el área andina para Perú (Contreras, 1988), Bolivia (Perreault, 2013), Argentina (Parodi y Benedetti, 2016) y Chile (Carmona, 2016; Calderón et al., 2016).

\section{Tipología de análisis}

Para el análisis de la cuestión agraria, presentamos una tipología de clases sustentada en los aspectos discutidos (Figura 1). Esta propuesta es de carácter general. No obstante, bajo ninguna circunstancia debe definirse deductivamente la presencia o no de tal o cual clase, en qué distribución y bajo qué procesos se llegó a determinada situación. Variará dependiendo de los espacios concretos, sus propios procesos históricos, por la forma que ahí adquiere el desarrollo capitalista y su participación en el mercado mundial. La tipología se construye de la siguiente forma: nominación de clase (primera columna), componentes estructurales definitorios y generales (segunda columna) y elementos que permiten precisar variaciones específicas (tercera columna).

\section{Metodología}

Abordamos la cuestión agraria y su relación con el extractivismo mediante un análisis de las transformaciones estructurales, las cuales son interpretadas 


\begin{tabular}{|c|c|c|}
\hline Clases agrarias & Característica estructural definitoria & Elementos de variabilidad \\
\hline Capitalistas & $\begin{array}{l}\text { Tienen propiedad respecto de los medios de producción. } \\
\text { Los hacen producir exclusivamente con fuerza de trabajo } \\
\text { asalariada. Su principal objetivo es la obtención de ganancia. }\end{array}$ & $\begin{array}{l}\text { Tamańo, procedencia (territorio, nacional o internacional), } \\
\text { residencia y destino de la producción, presencia de } \\
\text { dependientes no salariales, componentes étnicos. }\end{array}$ \\
\hline Terratenientes & $\begin{array}{l}\text { Propietarios de la tierra, pero no la usan productivamente, } \\
\text { cobran renta por su uso. }\end{array}$ & $\begin{array}{l}\text { Tamaño, procedencia (territorio, nacional o internacional), } \\
\text { residencia, componentes étnicos. }\end{array}$ \\
\hline $\begin{array}{l}\text { Campesinado } \\
\text { semi-capitalista }\end{array}$ & $\begin{array}{l}\text { Poseen propiedad o control sobre medios productivos a } \\
\text { escala que combina trabajo familiar con la compra decisiva } \\
\text { de fuerza de trabajo. }\end{array}$ & $\begin{array}{l}\text { Relaciones cooperativas o propiedades comunitarias / } \\
\text { individual, mercados de compraventa en que participa, } \\
\text { regularidad de la compra de trabajo, presencia de } \\
\text { dependientes no salariales, componentes étnicos. }\end{array}$ \\
\hline $\begin{array}{l}\text { Campesinado } \\
\text { medio }\end{array}$ & $\begin{array}{l}\text { Tienen propiedad o control sobre medios de producción } \\
\text { a escala donde pueden explotarlos solo con la familia, sin } \\
\text { compraventa de fuerza de trabajo. }\end{array}$ & $\begin{array}{l}\text { Relaciones cooperativas o propiedades comunitarias / } \\
\text { individual, mercados de compraventa en que participa, } \\
\text { componentes étnicos. }\end{array}$ \\
\hline $\begin{array}{l}\text { Campesinado } \\
\text { semi-proletario }\end{array}$ & $\begin{array}{l}\text { Son propietarios de medios productivos a baja escala, por } \\
\text { lo cual deben complementar el trabajo familiar predial con } \\
\text { sustancial venta de fuerza de trabajo. }\end{array}$ & $\begin{array}{l}\text { Relaciones cooperativas o propiedades comunitarias / } \\
\text { individual, mercados de compraventa en que participa, } \\
\text { forma de venta de trabajo salarial / no salarial (lugar, sector } \\
\text { económico, regularidad), componentes étnicos. }\end{array}$ \\
\hline $\begin{array}{l}\text { Asalariado con } \\
\text { tierra }\end{array}$ & $\begin{array}{l}\text { Genera su ingreso de modo mayoritario por la venta de } \\
\text { fuerza de trabajo, ya que no posee de medios de producción } \\
\text { propios. Sin embargo, controla minúsculos retazos de tierra } \\
\text { en los cuales siembra con fuerza de trabajo familiar. }\end{array}$ & $\begin{array}{c}\text { Procedencia (territorial, nacional extranjero), residencia } \\
\text { (urbano/rural), forma de venta de trabajo salarial / no } \\
\text { salarial (lugar, sector económico, regularidad), componentes } \\
\text { étnicos. }\end{array}$ \\
\hline Asalariado pleno & $\begin{array}{l}\text { No posee ni controla medios de producción bajo ninguna } \\
\text { modalidad. Depende plenamente de la venta de fuerza de } \\
\text { trabajo. }\end{array}$ & $\begin{array}{c}\text { Procedencia (territorial, nacional extranjero), residencia } \\
\text { (urbano/rural), forma de venta de trabajo salarial / no } \\
\text { salarial (lugar, sector económico, regularidad), componentes } \\
\text { étnicos. }\end{array}$ \\
\hline
\end{tabular}

Figura 1. Tipología general de clases sociales agrarias. Fuente: Elaboración propia.

y contextualizadas históricamente. Aplicamos un enfoque histórico-estructural sustentando en un diseño mixto de investigación.

La aproximación a la estructura agraria y su variación temporal, la realizamos a partir de un análisis detallado de los censos agropecuarios realizados en Chile (1929/30, 1935/36, 1955, 1964/65, 1975/76, 1996/97 y 2006/07), donde todos cuentan con información para el área de estudio. Primero identificamos y levantamos la información para luego confeccionar una base de datos mediante Microsoft Excel. Luego realizamos análisis estadísticos descriptivos univariados (y puntualmente bivariados) por año censal, con lo cual confeccionamos series temporales. Para responder las preguntas de investigación, tratamos las siguientes variables: i) número de explotaciones menores de 5 hectáreas; ii) número de hectáreas cultivadas en general; iii) número de hectáreas cultivadas por tipo de cultivos; iv) número de trabajadores según relación de trabajo, y; v) número de trabajadores según género.
La interpretación histórica de la dinámica estructural se sustenta en análisis de fuentes secundarias. Destacamos informes de viajeros, estudios técnicos y producción académica. Esta información fue sistematizada temáticamente de acuerdo a tres criterios: i) cambio agrario; ii) expansión del cobre, y; iii) otros fenómenos. Internamente la clasificamos por tiempo, lugar y proceso específico. La información que no cabía en tal diseño se agrupó en tópicos emergentes.

Posteriormente, realizamos un análisis comprensivo que integró ambas dimensiones con el propósito de dar cuenta de la evolución de la estructura agraria de la provincia estudiada, interpretar su desarrollo y relacionarlo con la expansión del cobre. Esta exposición, en el acápite respectivo, sigue un orden cronológico basado en cortes temporales según los años con censos agropecuario.

Algunos aspectos puntuales se analizan con base en datos etnográficos que hemos recopilado. 


\section{Área de estudio}

La provincia de El Loa está ubicada en la precordillera y cordillera de la región de Antofagasta, norte de Chile. Administrativamente, se divide en las comunas de Calama, Ollagüe y San Pedro de Atacama (Figura 2).

Forma parte de la puna salada del desierto de Atacama, área que se compone de tres pisos ecológicos: oasis y salares (2100-3100 msnm), quebradas intermedias y altas (3100-3850 msnm), y la alta puna (3850-4250 msnm) (Núńez y Santoro, 1988).
Sus principales cuencas son la del río Loa y la del salar de Atacama, las que, a su vez, son las más relevantes de la región de Antofagasta. Concentran el 68\% del total regional de aguas asignadas por el Estado (Calderón y Prieto, 2019). También son los principales espacios regionales de actividad agropecuaria (Arrau Ingeniería E.I.R.L., 2012).

Es un espacio que históricamente ha sido habitado por población indígena andina, identificada actualmente como likan antai o atacameńa, y en menor medida quechuas. También hay presencia aymara que se debe a dinámicas de movilidad.

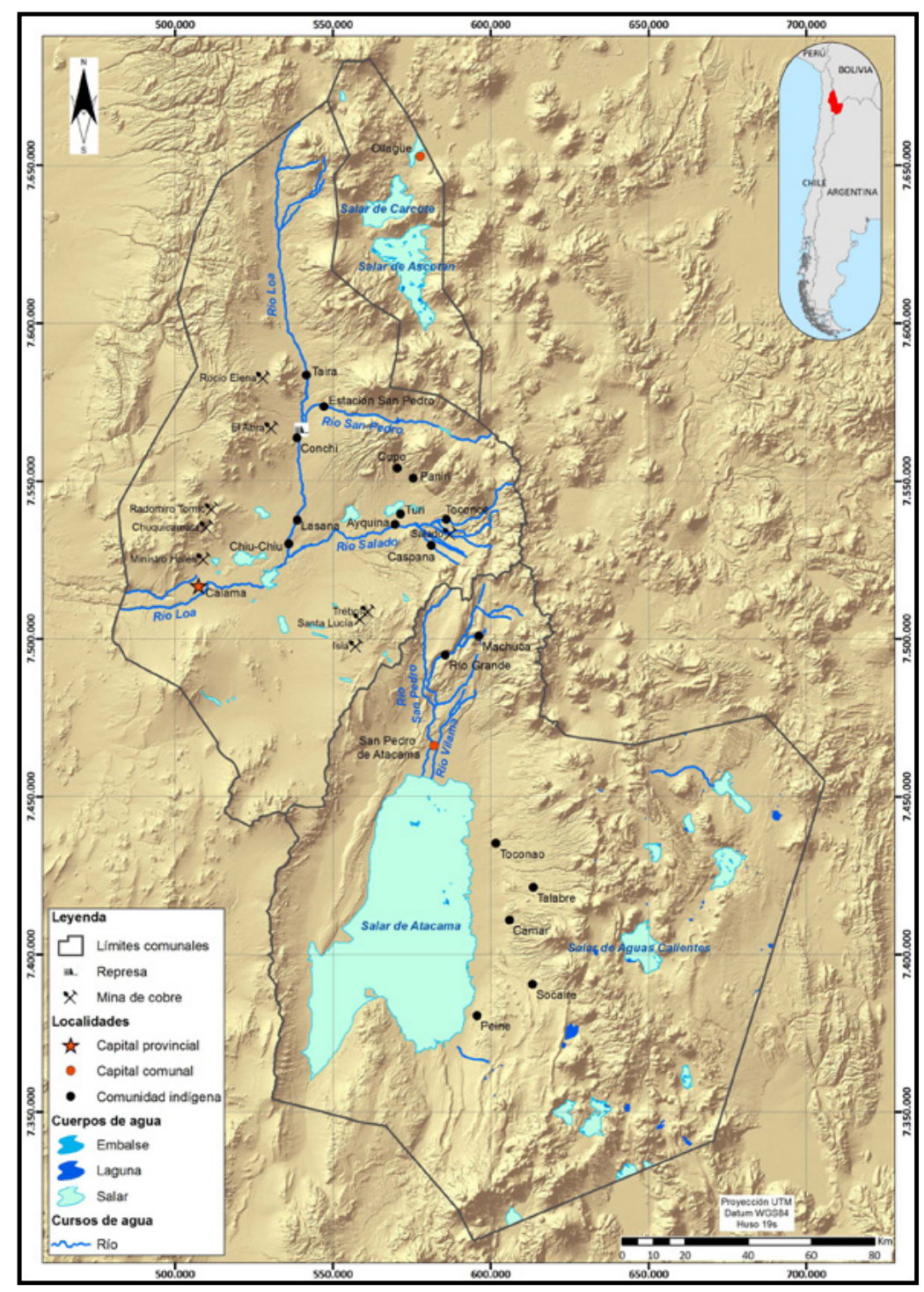

Figura 2. Mapa de la provincia de El Loa. Fuente: FONDECYT 11150130. 


\section{Antecedentes básicos de la cuestión agraria anterior al cobre}

Según diversas fuentes (Aldunate et al. 1986; Núñez, 1995; Castro y Martínez, 1996, entre otros), la población indígena de la provincia de El Loa ha practicado históricamente actividades agropecuarias, de intercambio y pequeña minería, con uso complementario de los distintos pisos ecológicos. La agricultura se desarrolló en quebradas, vegas y oasis, en torno a los cuales se constituyeron asentamientos permanentes. La ganadería se ejecutó mediante pastoreo en estancias a mayor altura. Eran emplazamientos dispersos y estacionales, cercanos a humedales altoandinos, ricos en agua y forraje. A su vez, se establecieron complejos sistemas de intercambio de sus excedentes que los articularon a diversas regiones del espacio andino.

Estudios de larga resolución temporal constatan el dinamismo de este modelo; el que, desde tiempos prehispánicos, experimentaba sus propias transformaciones (Aldunate et al., 1986; Núñez, 1995). Empero, la inserción al mercado mundial a través de la situación colonial y posterior desarrollo de Estados independientes impulsó reconfiguraciones profundas de las actividades económicas de la población y sus formas de ocupar el territorio. Revisaremos algunos aspectos claves previos al desarrollo de la gran minería cuprífera.

\section{Despojo de la tierra}

La situación colonial conllevó el despojo de parte de las tierras de propiedad indígena, siendo un hito clave de acumulación originaria que posibilitó la expansión capitalista. Las tierras de oasis de altura media quedaron en gran medida bajo propiedad no indígena, mientras que las tierras indígenas se circunscribieron a mayores alturas. Esto ocurre tempranamente en Calama (Gundermann, 1998), mientras que en San Pedro de Atacama se consolida en el siglo XIX (Barros, 2008). Ambos casos están motivados por el interés que despertaron estos poblados al ubicarse en rutas arrieras y poseer potencial agropecuario. Se constituyeron en espacios de engorda y descanso del ganado que transitaba por la ruta costa-altiplano, en el caso de Calama, y Argentina-salitreras, en San Pedro de Atacama.

\section{Incorporación de cultivos y animales}

Desde el siglo XVI se van incorporando cultivos y animales europeos a la actividad agropecuaria indígena (Núnez, 1995). Destaca el trigo, la alfalfa, la vid y frutales; y en términos ganaderos, los caprinos, ovinos y vacunos. En el siglo XVII los elementos foráneos están plenamente internalizados, incluso se incorpora el manejo trashumante de ovinos en humedales. Otro ejemplo está en la incorporación de mulares durante el siglo XVII a labores de tráfico reemplazando a la llama (Sanhueza, 1992).

\section{Proletarización e ingreso monetario}

El despojo de tierras configuró, por una parte, la necesidad de los propietarios de contratar jornaleros, y por la otra, que hubiese personas dispuestas o necesitadas de asalariarse. Gundermann (1998) identifica que en Calama se empieza a depender del uso de jornales remunerados durante el régimen colonial. Algo similar observa Bowman (1942) en San Pedro de Atacama a inicios del siglo XX. También durante la Colonia destaca la conformación de pequeñas empresas de arrieraje en las que los indígenas participaban, a veces como asalariados y otras como cuentapropistas (Sanhueza, 1992). En el mismo período se desarrollaron procesos de proletarización hacia actividades mineras en yacimientos de Potosí y Lípez. La población se movilizaba estacionalmente con distintos grados de permanencia (Rivera, 1995).

Desde el siglo XVII se introdujeron necesidades de consumo que debían proveerse vía mercado (p.e., la compra de mulas). Otro aspecto que también aumentó los requerimientos de ingreso en dinero era la exigencia colonial de pagar un tributo monetario (Sanhueza, 1992).

En la primera mitad del siglo XIX, a las formas de proletarización e ingreso monetario indicadas se añade la venta de fuerza de trabajo en faenas mineras en el área de estudio (mina Caracoles, pequeños yacimientos en área de Chuquicamata y minería no metálica de altura). Esto impulsa la llegada de población indígena de asentamientos interiores y la puna, que se instala estacional o definitivamente en 
centros mineros o cercanías de Calama (Sanhueza y Gundermann, 2007).

Durante la segunda mitad del siglo XIX, se debilitó el tráfico costa-altiplano vía Calama por la construcción del ferrocarril Antofagasta-Bolivia y la disminución de la minería en el sur boliviano. Esto reduce el dinamismo económico de Calama en torno al arrieraje (Sanhueza y Gundermann, 2007). Sin embargo, San Pedro de Atacama emergió como lugar de tránsito arriero entre Argentina y las industrias salitreras, dotando a la zona de alta actividad económica (Bowman, 1942). Se consolidó el control afuerino de las mejores tierras (Barros, 2008), lo que sentó las bases para la presencia de trabajo asalariado en labores agrarias, ganaderas y arrieraje, fenómeno observado por Bowman (1942) a inicios del siglo XX.

La proletarización, a pesar de ir en crecimiento, no era la forma dominante de generación de ingresos en la población indígena. Se constituye en complemento de las actividades agropecuarias ejecutadas con trabajo familiar y comunitario. Hasta antes del inicio de operaciones de Chuquicamata, en la población indígena predominaron unidades domésticas de tipo campesino semiproletario, aunque con múltiples grados e intensidades. Es más, hasta mediados del siglo XX, a pesar de los procesos que tendían a su debilitamiento, el sistema asentamiento-estancia siguió operando en distintos espacios de la provincia (Castro y Martínez, 1996; Gundermann, 1998).

\section{Antecedentes para situar la cuestión agraria en los siglos XX y XXI}

Presentamos distintos aspectos que dan cuenta del contexto donde se desarrolla la cuestión agraria en este período y que son de relevancia para comprenderla.

\section{Crecimiento urbano}

La expansión cuprífera se concatena con un crecimiento vertiginoso de la población urbana de la provincia, ${ }^{6}$ específicamente de Calama, del com-

6 Seguimos la clasificación censal. Los asentamientos urbanos poseen población mayor a 2000 personas o entre 1001 y 2000 , donde menos del $50 \%$ se dedica pany town de Chuquicamata ${ }^{7}$ y recientemente de San Pedro de Atacama. ${ }^{8}$ En el Censo de 1907, la población total de la provincia eran 9525 personas. De ellas, el $30 \%$ del total eran urbanas (solo Calama) y el 70\%, rurales (Comisión Central del Censo, s.f.). En el Censo de 1920, la población total de la provincia llegaba a 18699 habitantes, de los cuales el 75\% del total eran urbanos (Calama y Chuquicamata) y el 25\%, rurales (Dirección General de Estadística, 1925). La población urbana aumenta progresivamente hasta llegar al momento actual con 177048 personas, de las cuales el 93\% del total es urbana (Calama y San Pedro de Atacama) y el 7\% rural (INE, 2018). La comuna con mayor población es Calama, con 165731 personas (94\% del total provincial); de estas, el $96 \%$ se emplaza en zonas urbanas. En el municipio de San Pedro de Atacama se registraron 10996 personas $(6 \%$ del total provincial), distribuidas equitativamente entre espacios urbanos y rurales. En la comuna de Ollagüe se censaron solo 321 personas.

\section{Urbanización indígena}

En el Censo 2017 (INE, 2018), 45462 personas se declararon parte de un pueblo originario a nivel provincial (26\% de la población total provincial). Dentro de ellas, un $49 \%$ se identificó likan antai; un $17 \%$, quechua y $12 \%$, aymara. La comuna con mayor presencia absoluta de indígenas es Calama con 39724 personas (24\% del total comunal), luego San Pedro de Atacama con 5523 (50\% del total comunal) y finalmente Ollagüe con 215. En Calama, los likan antai corresponden a cerca de la mitad de la población indígena, con el 46\% (18 100 personas), mientras que en San Pedro de Atacama, con 4068 personas, son el $74 \%$ del total indígena.

Predomina el emplazamiento urbano de los indígenas. El 2017 (INE, 2018), del total de indígenas de

a actividades primarias. Los asentamientos rurales tienen población igual o menor a 1000 habitantes, o entre 1001 y 2000, donde más del 50\% declaró dedicarse a actividades primarias.

7 Cierra el 2007 por expansión de la mina, sus habitantes son trasladados a Calama.

8 Desde la década del dos mil hay crecimiento poblacional asociado al turismo, con lo cual es calificado como urbano. 
la provincia, el $89 \%$ habita en sectores urbanos y $11 \%$ en rurales. Dentro de la población indígena urbana, el $47 \%$ es likan antai; $18 \%$, quechua y $12 \%$, aymara; mientras que dentro de la población indígena rural, el $62 \%$ es likan antai; $13 \%$, quechua, $11 \%$, mapuche 9 y $8 \%$, aymara. A nivel interno de cada pueblo, el $86 \%$ de los likan antai se ubica en espacios urbanos, el $92 \%$ de los quechuas y el $92 \%$ de los aymara.

\section{Desagrarización del ingreso indígena}

Se ha configurado un escenario donde las actividades extractivas, industriales y de servicios son las principales fuentes de sustento de la población indígena, mientras que las agropecuarias han sido relegadas. El 2017 (INE, 2018), dentro de la población indígena ocupada, un $2 \%$ del total provincial se dedicó a la agricultura; un $14 \%$, a la minería e industrias manufactureras y un $84 \%$ trabaja en empleos de servicios urbanos de diverso tipo. ${ }^{10}$ Dentro de los likan antai ocupados, un $3 \%$ del total provincial lo hace en la agricultura; un $15 \%$, en minería e industrias manufactureras y el $82 \%$, en servicios urbanos. ${ }^{11}$ Entre quechuas y aymaras, la ocupación agraria es menor, con un $1 \%$ del total provincial en cada etnia. El resto de la población ocupada de estas etnias tiene una composición similar a lo ya expresado.

En consecuencia, la cuestión agraria analizada acontece en un contexto donde ha dejado de ser el principal sustento de la población indígena.

\section{Privatización y despojo de las aguas}

Los recursos hídricos están en el centro de la expansión del extractivismo cuprífero. Su crecimiento, como el aumento de la población urbana regional, ha impulsado una creciente demanda por las aguas de los sectores altos del río Loa y en el salar de Ata-

9 Forma parte de procesos de migración de escala nacional impulsados por el extractivismo. Tiene presencia mayoritaria en Calama, donde representan el 19\% de la población indígena rural.

10 Resaltan comercio (14\%), construcción (8\%) y transporte y almacenamiento (8\%).

11 Destacan comercio (13\%), transporte y almacenamiento $(9 \%)$ y servicios administrativos y de apoyo (7\%). cama. ${ }^{12}$ Como parte de la acumulación originaria del extractivismo, ha acarreado distintos episodios de despojo de las aguas de las poblaciones indígenas, como también apropiaciones respaldadas por la ley ${ }^{13}$ (Yáñez y Molina, 2011). Al año 2018, La provincia de El Loa concentra el 73\% del total de derechos de agua de la región de Antofagasta. A nivel interno de la provincia, el 46\% del total de aguas asignadas corresponde a minería; $17 \%$, riego; $15 \%$, sanitario; $10 \%$, industrial, y un $12 \%$ asociado a otros usos. En síntesis, los usos extractivos, sanitarios e industriales concentran el $71 \%$ del total de litros por segundo asignados en la provincia (Calderón y Prieto, 2019).

\section{Otras dinámicas a considerar: litio y turismo}

Desde 1984 se expande la gran minería de salmueras (litio y potasio) en el salar de Atacama. Actualmente, se constituye en una de las principales fuentes de litio para el mercado mundial. Esto ha llevado a transformaciones sociales y disputas por recursos naturales de distinto tipo entre empresas y poblaciones indígenas (Gundermann y Göbel, 2018).

Durante la década del noventa, se desarrolla una actividad turística masiva, controlada por afuerinos que, nucleadas en San Pedro de Atacama, afecta al conjunto de poblados en torno al salar. Destaca el crecimiento poblacional y expansión espacial de San Pedro, reconfiguración de su casco histórico, gentrificación rural, pérdida de tierras de los atacameños, mayor demanda de agua, entre otros (Molina, 2019).

$\mathrm{Al}$ analizar la cuestión agraria, debemos tener presente para las décadas recientes que se añaden al extractivismo cuprífero, la gran minería de litio y el turismo masivo en el salar de Atacama.

12 La principal demanda de agua en este salar es por la gran minería de litio. También hay demanda hídrica desde la actividad cuprífera, pero son minas que no están en la provincia, sino en otras partes de la región, por ejemplo, Minera Escondida (actualmente la más grande del país y del mundo).

13 Entre las causas del despojo, destacamos el Código de Aguas de 1981 como marco legal de la privatización de los derechos de agua. 


\section{La cuestión agraria en el siglo XX y su conexión con el cobre}

Como vimos, entre algunas características de la cuestión agraria previa al desarrollo del extractivismo cuprífero están las diversas formas de participación en mercados y los procesos de diferenciación relativos a proletarización e ingreso monetario. El carácter de clase mayoritario de las unidades domésticas era el de campesinos con diferentes grados de proletarización y articulación mercantil.

Un indicador del carácter campesino de las explotaciones agropecuarias se revela al observar su tamaño. En el año agrícola de 1929-30, el 90\% del total de explotaciones son menores de 5 ha (Dirección General de Estadística, 1933). A su vez, al ver su evolución en el tiempo (Figura 3), ${ }^{14}$ tienen presencia mayoritaria. En este sentido, el desarrollo del extractivismo cuprífero y sus dinámicas concatenadas no han afectado el tamaño de las explotaciones. El proceso de proletarización no ha sido hacia un capital agrario que impulse una concentración de la tierra, sino hacia empleos mineros, urbanos y de servicios que no inciden en este aspecto.

Establecido este aspecto, destacamos que, tal como se observó para el período anterior a la llegada del capital cuprífero, en 1929-30, se siguen identificando componentes capitalistas en la actividad agropecuaria. El hecho de que el 5\% del total de explotaciones contara con un administrador pagado (Dirección General de Estadística, 1933) expresa la constitución de un propietario de la tierra que se separó de las labores de gestión y como productor directo. En los relatos de Bowman (1942), es posible identificar a productores capitalistas y semicapitalistas con presencia en los oasis de Calama y San Pedro de Atacama, quienes ocupaban peones pagados para actividades agrícolas y ganaderas. Destaca el cultivo de alfalfa para alimentar el ganado que se llevaba a las minas y centros urbanos, concentrando el $79 \%$ del total de la tierra cultivada (Figura 4);15 cultivo que también estaba

14 Gráfico de referencia para todas las menciones al tamaño de las explotaciones.

15 Gráfico de referencia para todas las menciones al porcentaje de usos del suelo. internalizado en la agricultura indígena campesina (Núñez, 1995).

Cultivos con menor presencia en relación al uso del suelo son el maíz $(8 \%)^{16}$ y el trigo $(7 \%)^{17}$, que se relacionan directamente a la agricultura indígena campesina de espacios de mayor altura. Por ejemplo, las localidades del Loa alto y afluentes (Figura 5) no habían internalizado relaciones capitalistas en su seno agrícola, debido a su lejanía de los principales puntos de circulación. Recibían salario cuando se movilizaban a los oasis de menor altura o en las faenas mineras (Hanson, 1926). Los cultivos de alfalfa, maíz, trigo y hortalizas que se observan en estas localidades tienen como destino el autoconsumo (Risopatrón, 1918; Walcott, 1925; Hanson, 1926; Rudolph, 1928). La excepción es Chiu Chiu que, debido a su cercanía a Calama y la company town de Chuquicamata, combina tempranamente la agricultura para autoconsumo y mercado (Risopatrón, 1905; 1918).

Además de la venta de fuerza de trabajo para las faenas mineras, en actividades agropecuarias en Calama y San Pedro de Atacama, y arrieraje, adquiere relevancia la extracción y venta de yareta (Azorella compacta). Es una planta presente en la puna de los Andes centro-sur, usada como combustible por la población local, ciudades, industrias extractivas y ferrocarriles (Hodge, 1960). Era extraída con fuerza de trabajo familiar no remunerada y transportada en caravanas de mulas, burros, llamas, y luego camiones, para ser vendida a intermediarios (Risopatrón, 1905; 1918; Walcott, 1925; Hanson, 1926). Fue el principal combustible usado por el campamento de Chuquicamata y la ciudad de Calama hasta fines de la década del cincuenta e inicios de los sesenta (Hodge, 1960). Según nuestros registros etnográficos, la venta y extracción de yareta se mantuvo como una de las principales formas de ingreso monetario hasta la década del sesenta.

16 Las cifras de maíz combinan para todo el período estudiado los cultivos de maíz para grano seco y maíz choclo. El primero es consignado en la mayoría de los censos como maíz (grano seco), mientras que el segundo es nominado como maíz en 1920-30, choclo (maíz) en 1964-65 y 1975-76, y choclo en 1996-97 y 2006-07.

17 Las cifras de trigo combinan para todo el período estudiado los cultivos de trigo blanco y trigo candeal. 


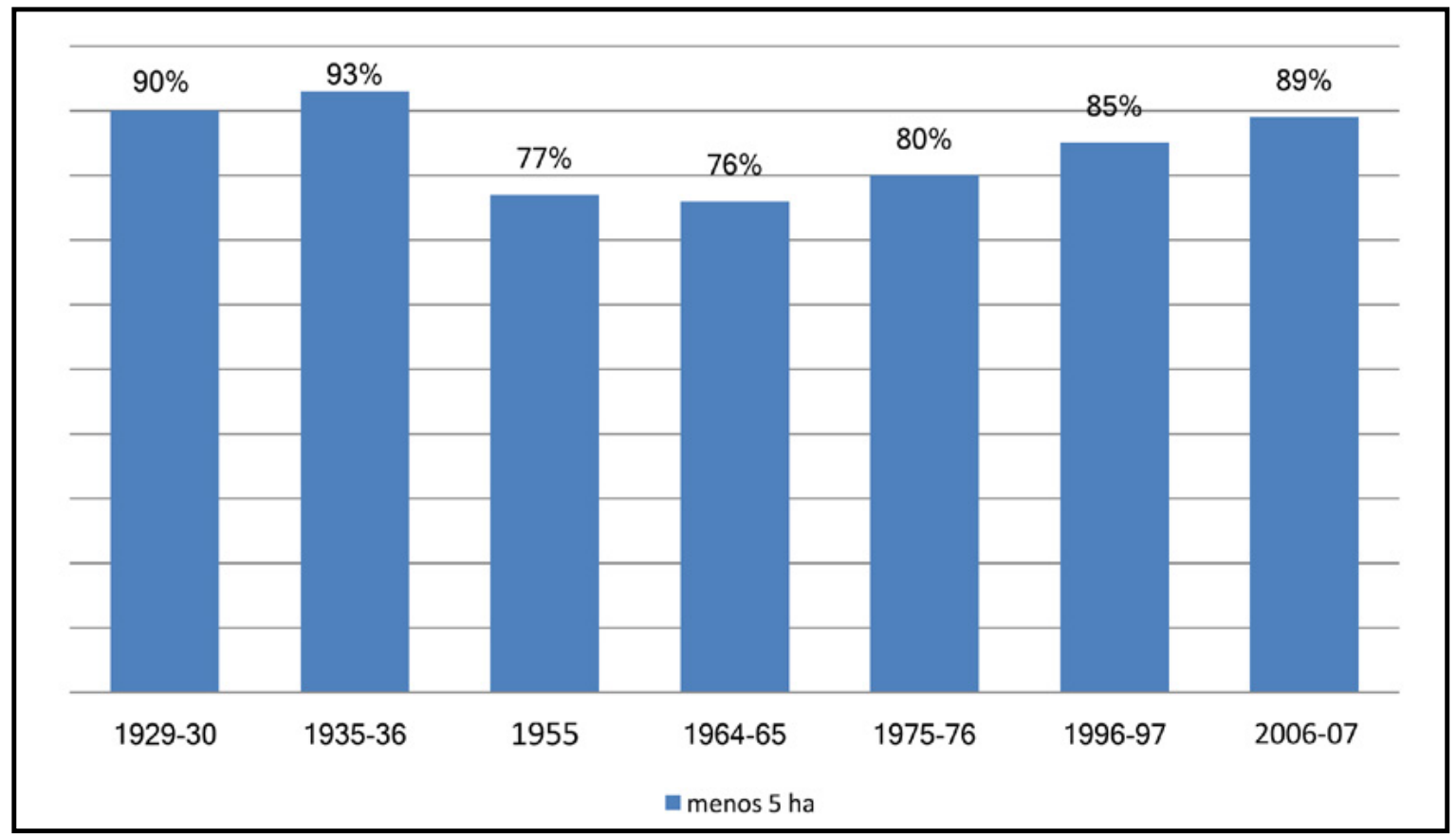

Figura 3. Explotaciones menores de 5 ha en la provincia de El Loa (1929-30 a 2006-07). Fuente: Elaboración propia con datos de la Dirección General de Estadística (1933; 1938); Servicio Nacional de Estadística y Censos (1955); Dirección de Estadística y Censos (1969); INE (1980; s.f.-a; s.f.-b) y Oficina de Estudios y Políticas Agrarias (s.f.).

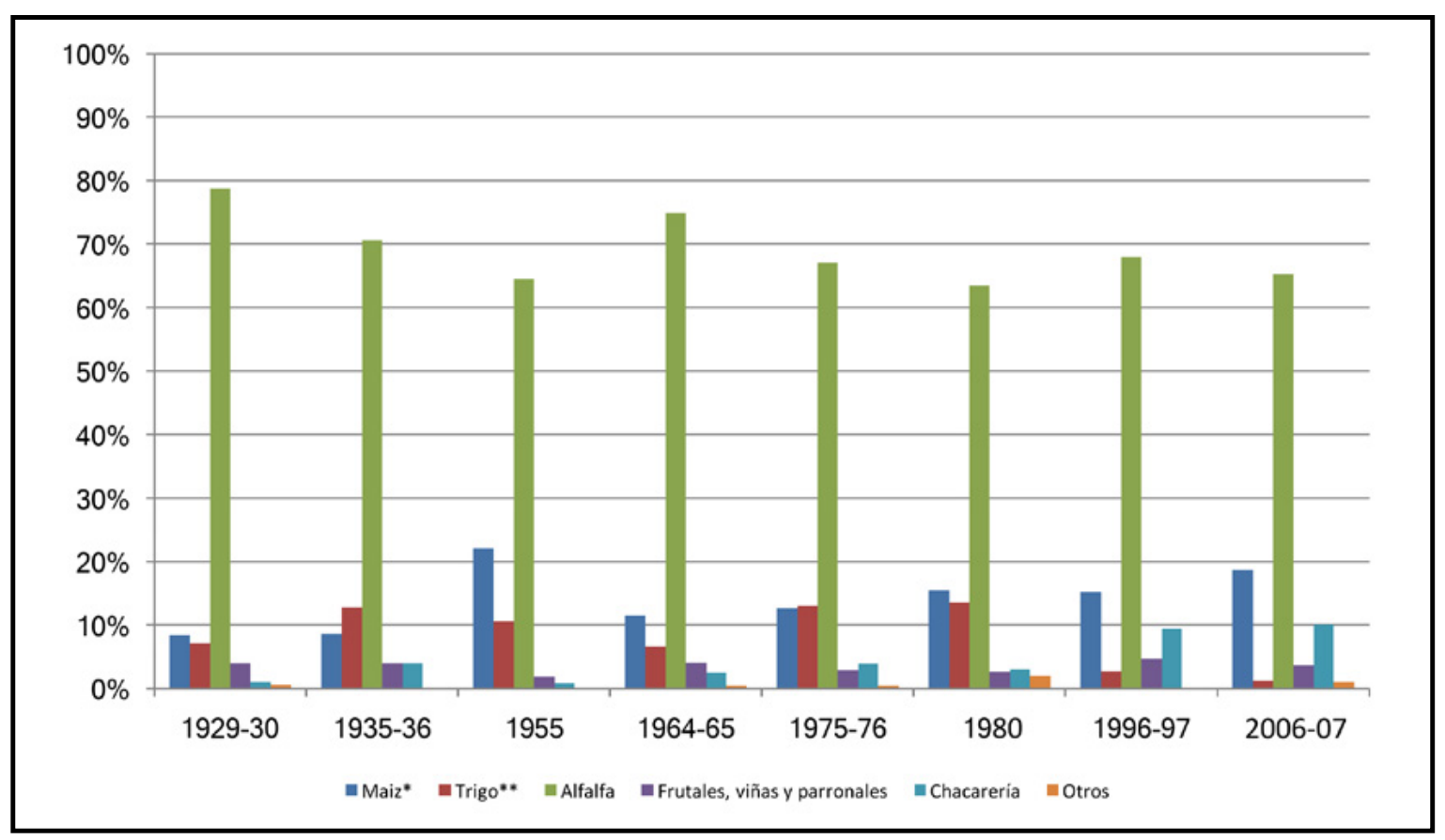

Figura 4. Gráfico de porcentaje de hectáreas sembradas y plantadas en la provincia de El Loa por cultivos principales (1929-30 a 2006-07). Fuente: Elaboración propia con datos de la Dirección General de Estadística (1933; 1938); Servicio Nacional de Estadística y Censos (1955); Dirección de Estadística y Censos (1969); INE (1980; s.f.-a; s.f.-b), Consecol (1988) y ODEPA (s.f.). 


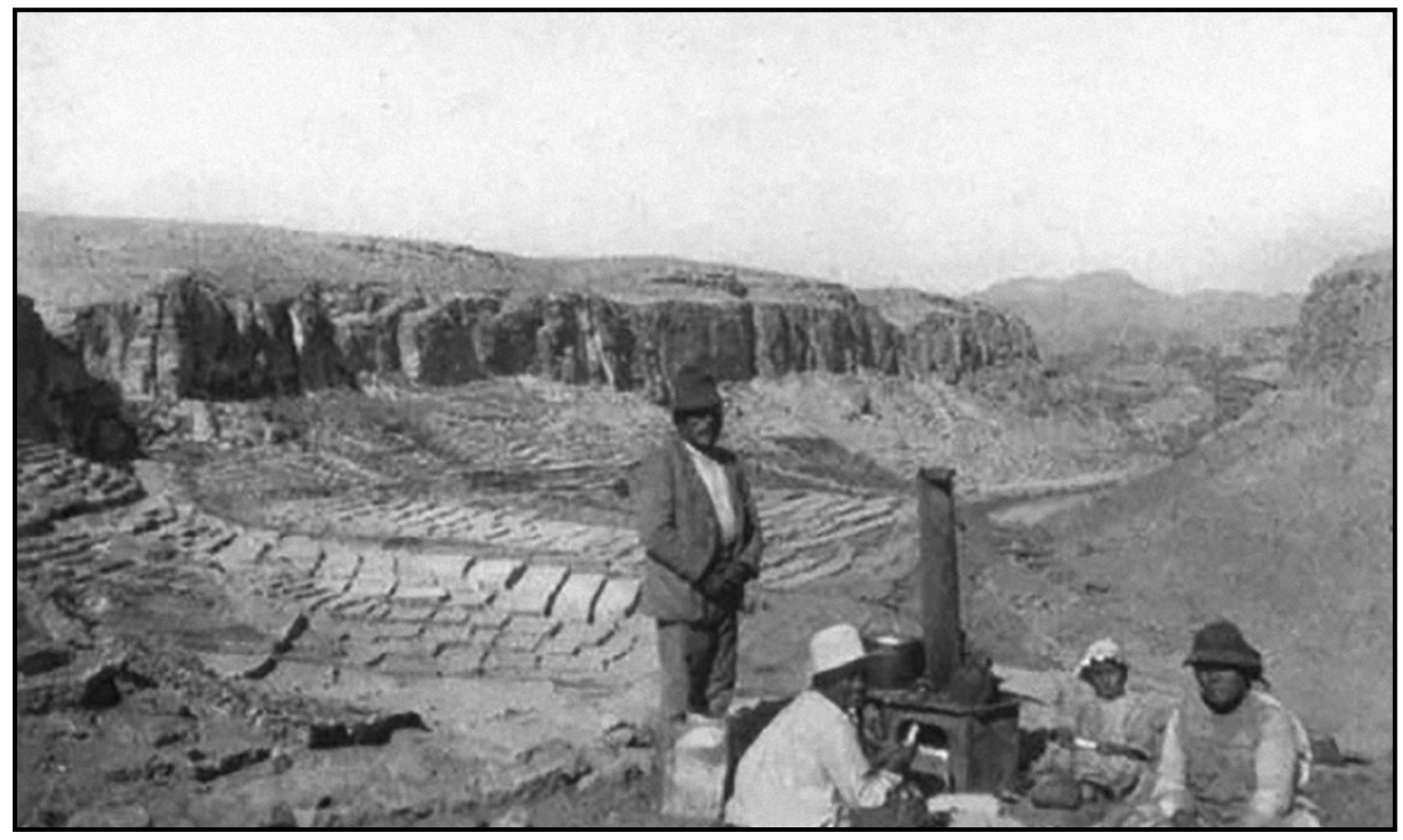

Figura 5. Habitantes de Ayquina y panorámica a terrazas de cultivos en los primeros ańos de la década del veinte. Fuente: Hanson (1926).

En el año agrícola 1935-36, vemos algunas expresiones del decaimiento de San Pedro de Atacama como punto de circulación de arrieraje. Una de las principales fue la reducción de los alfalfales (Rivera, 1995). Esto llevó una disminución del total de las hectáreas cultivadas (Figura 6), ${ }^{18}$ debido a una baja de la tierra dedicada a la alfalfa. Contrariamente, existe un incremento de alimentos como el trigo y la chacarería (Figura 7). ${ }^{19}$ Sostenemos que el vuelco hacia la agricultura familiar, que privilegie el autoconsumo, fue una primera estrategia de la población indígena de San Pedro de Atacama ante la crisis del arrieraje, disminución en los cultivos de la alfalfa y menor ingreso monetario. Fue un movimiento que buscó fortalecer la base agraria de tipo campesino como actividad económica. Es conocido que esta primera estrategia no habría prosperado, constatándose posteriormente emigración y debilitamiento agropecuario (Aranda, 1961).

18 Gráfico de referencia para todas las menciones al número de hectáreas totales.

19 Gráfico de referencia para todas las menciones al uso del suelo absoluto por cultivos.
Para la cuenca del río Loa, algunas fuentes cercanas (Rudolph, 1928) permiten figurar una agricultura de orientación mercantil en Calama, y en menor medida en Chiu Chiu, con presencia de alfalfa, trigo y chacarería. El aumento de este último rubro expresaría el ingreso de agricultura de mercado. En décadas posteriores, hasta la actualidad, hortalizas y similares se constituyeron en los principales productos de mercado de Chiu Chiu y Lasana. Relatos etnográficos que hemos registrado describen como, ya a mediados del siglo $\mathrm{XX}$, tanto Calama como Chuquicamata compraban hortalizas a Chiu Chiu y Lasana para alimentar a la población urbana. Por esta fecha, la agricultura mercantil entra en una fase de transición a una mayor articulación debido a la expansión del cobre experimentada desde 1955.

En la década del cincuenta, se detectó presencia de alfalfa, maíz, trigo y hortalizas en la generalidad de los asentamientos de la provincia, más allá del destino de la producción y superficies cultivadas (Lobos, 1951). En el Censo Agrícola Ganadero de 1955 hay un aumento de las hectáreas cultivadas totales que se debe al incremento del maíz y la alfalfa. El maíz 


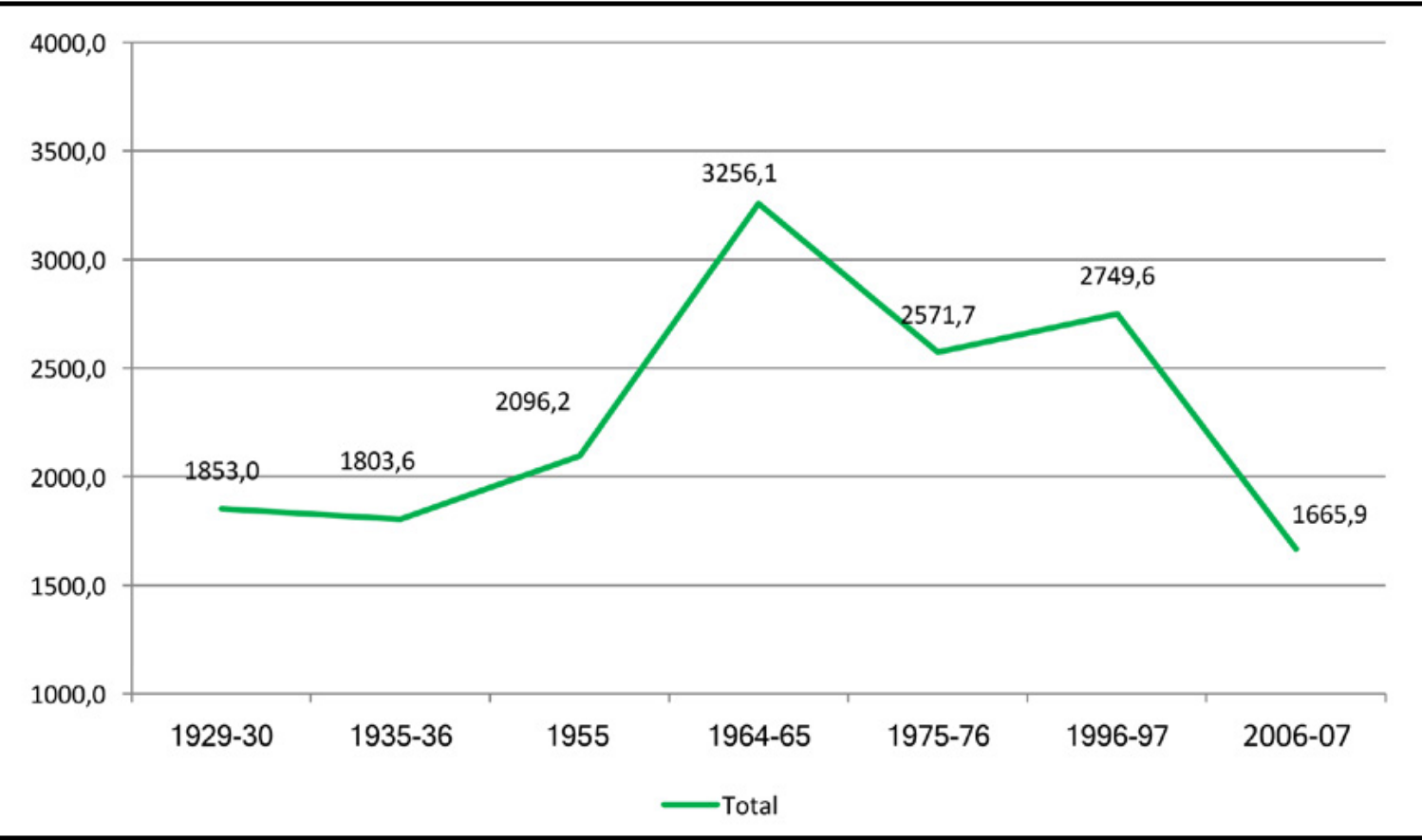

Figura 6. Hectáreas sembradas y plantadas en la provincia de El Loa (1929-30 a 2006-07). Fuente: Elaboración propia con datos de la Dirección General de Estadística (1933; 1938); Servicio Nacional de Estadística y Censos (1955);

Dirección de Estadística y Censos (1969); INE (1980; s.f.-a; s.f.-b) y ODEPA (s.f.).

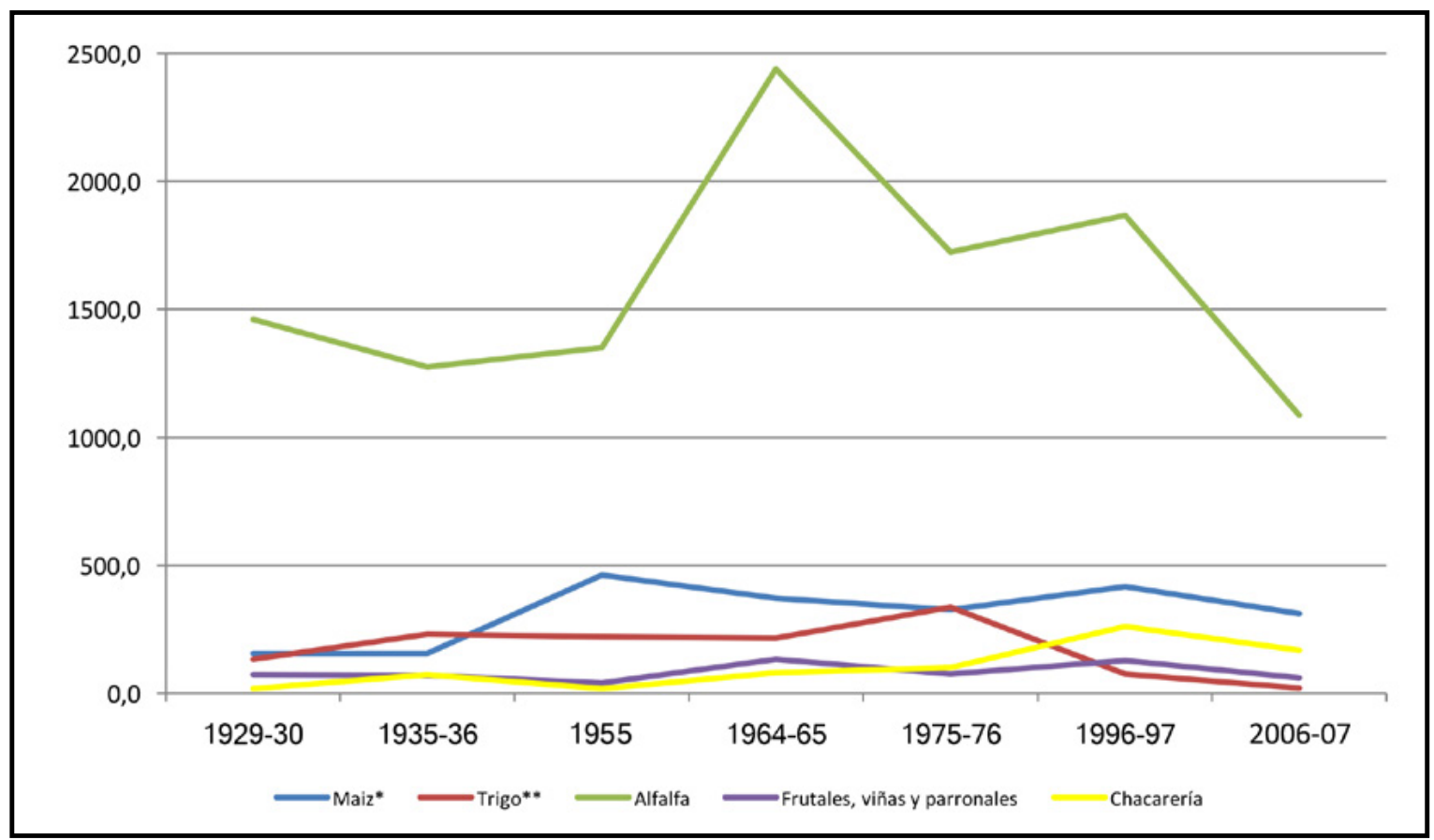

Figura 7. Hectáreas sembradas y plantadas en la provincia de El Loa por cultivos principales (1929-30 a 2006-07). Fuente: Elaboración propia con datos de la Dirección General de Estadística (1933; 1938); Servicio Nacional de Estadística y Censos (1955); Dirección de Estadística y Censos (1969); INE (1980; s.f.-a; s.f.-b) y ODEPA (s.f.). 
sube del 8,6 al 22\% del total del uso del suelo, mientras que la alfalfa, a pesar de su incremento absoluto, baja del 71 al 65\% del total del mismo parámetro.

Por estos años, las menores posibilidades de obtener ingreso asalariado en San Pedro de Atacama, en una población que había internalizado su uso, agudizó las dificultades económicas en este espacio. Por consiguiente, la expansión de la alfalfa, rubro vinculado a agricultura capitalista articulada a mercados urbanos y extractivos, debe interpretarse como ocurrida en el oasis de Calama. Rudolph (1951) destacó la fluida vinculación comercial del agro de Calama con Chuquicamata, entre los cuales se tranzan frutas, hortalizas, carne y subproductos ganaderos, tales como leche y crema. Empero, a pesar de estar debilitada, refiere a la existencia de ventas a baja escala de algunas frutas y verduras, desde San Pedro de Atacama hacia Calama y Chuquicamata. Con todo, en San Pedro de Atacama, las principales fuentes de trabajo están por esos ańos fuera de la actividad agropecuaria, predominando la venta de trabajo en las minas de la zona (Wiedmaier, 1957).

El aumento sustancial de hectáreas destinadas al maíz puede deberse a distintas razones simultáneas. Por una parte, el volcamiento hacia productos tradicionales destinados a consumo o intercambio en San Pedro de Atacama y sus alrededores. A pesar de las dificultades referidas, la caracterización que hace Barthel (1986) de Socaire en 1957 da cuenta de una diversidad de productos agrícolas (300 ha de papas, maíz, cereales y quinua), cuya mayoría se intercambiaba recíprocamente. Por otra parte, es factible un incremento de las siembras de maíz en el oasis de Calama, pero en este caso, con articulación al mercado urbano. Constatamos etnográficamente que el maíz que se siembra en Calama, hasta la actualidad, se destina en una porción relevante a los mercados.

En las localidades del río Salado (afluente del Loa), aparecen las primeras menciones sobre venta de frutas y hortalizas a Chuquicamata y Calama $(\mathrm{Ru}-$ dolph, 1951). Este dato muestra una agricultura campesina vinculada a mercados en una zona donde no se presentaba con claridad previamente. Un fenómeno conectado sería el fortalecimiento transitorio de la actividad agrícola como estrategia inicial de la población ante el desecamiento de humedales usados para pastoreo en el río San Pedro de Inacaliri (Martínez, 1985).

En Chiu Chiu, se fortaleció el proceso de proletarización de parte de jóvenes hacia la actividad minera, dando un carácter mucho más nítido de unidades campesinas semiproletarias, vinculadas al mercado, pero de modo precario (Rudolph, 1951). Nuestras entrevistas etnográficas confirman lo anterior, refiriendo a dinámicas simultáneas de agricultura mercantil y proletarización urbana y minera.

El Censo de 1955 nos proporciona información detallada sobre la fuerza de trabajo agraria, permitiéndonos profundizar en el carácter de las relaciones de producción. De 1683 trabajadores (Figura $8^{20}$ ), el $76 \%$ se vinculó mediante relaciones no remuneradas (Figura $9^{21}$ ). Internamente en los trabajadores no remunerados, hay predominancia de hombres, con un 55\% del total de ellos (Servicio Nacional de Estadística y Censos, 1955).

En lo que respecta al trabajo asalariado, observamos internamente una mayoría de empleados temporeros, con un $77 \%$ del total de trabajadores asalariados y solo un 23\% de permanentes. En ambos casos la presencia masculina es sobre el 90\% (Servicio Nacional de Estadística y Censos, 1955).

Entre las décadas del cincuenta y sesenta, los oasis de altura media de la cuenca del río Loa (Calama, Chiu Chiu y Lasana) fortalecieron su articulación con los mercados. En el año agrícola 1964-65, se constató un fuerte aumento de la superficie cultivada en la provincia, desde 2096 a 3256 ha. Esto da cuenta de una mayor intensidad de vínculos mercantiles. El principal cultivo en incrementarse fue la alfalfa, con poco más de 1000 ha adicionales respecto al censo anterior. Junto con ello, hay un ascenso relevante de la chacarería desde 17 a 81 ha (Dirección de Estadística y Censos, 1969).

El aumento de los cultivos de alfalfa lo relacionamos al crecimiento sostenido de la extracción de

20 Gráfico de referencia para todas las menciones al número absoluto de trabajadores por tipo.

21 Gráfico de referencia para todas las menciones al número porcentual de trabajadores por tipo. 


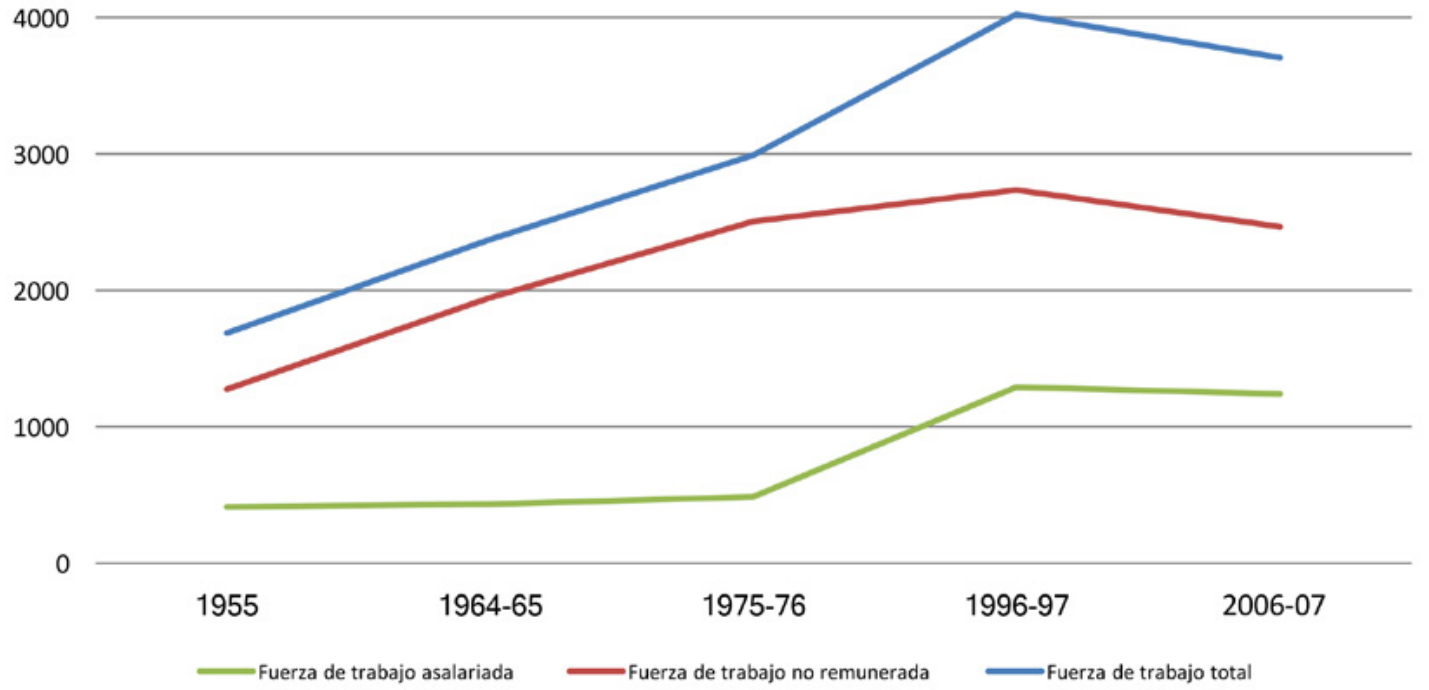

Figura 8. Carácter de la fuerza de trabajo agrícola en la provincia de El Loa (número de personas) (1955 a 2006-07). Fuente: Elaboración propia con datos del Servicio Nacional de Estadística y Censos (1955);

Dirección de Estadística y Censos (1969); INE (1980; s.f.-a; s.f.-b) y ODEPA (s.f.).

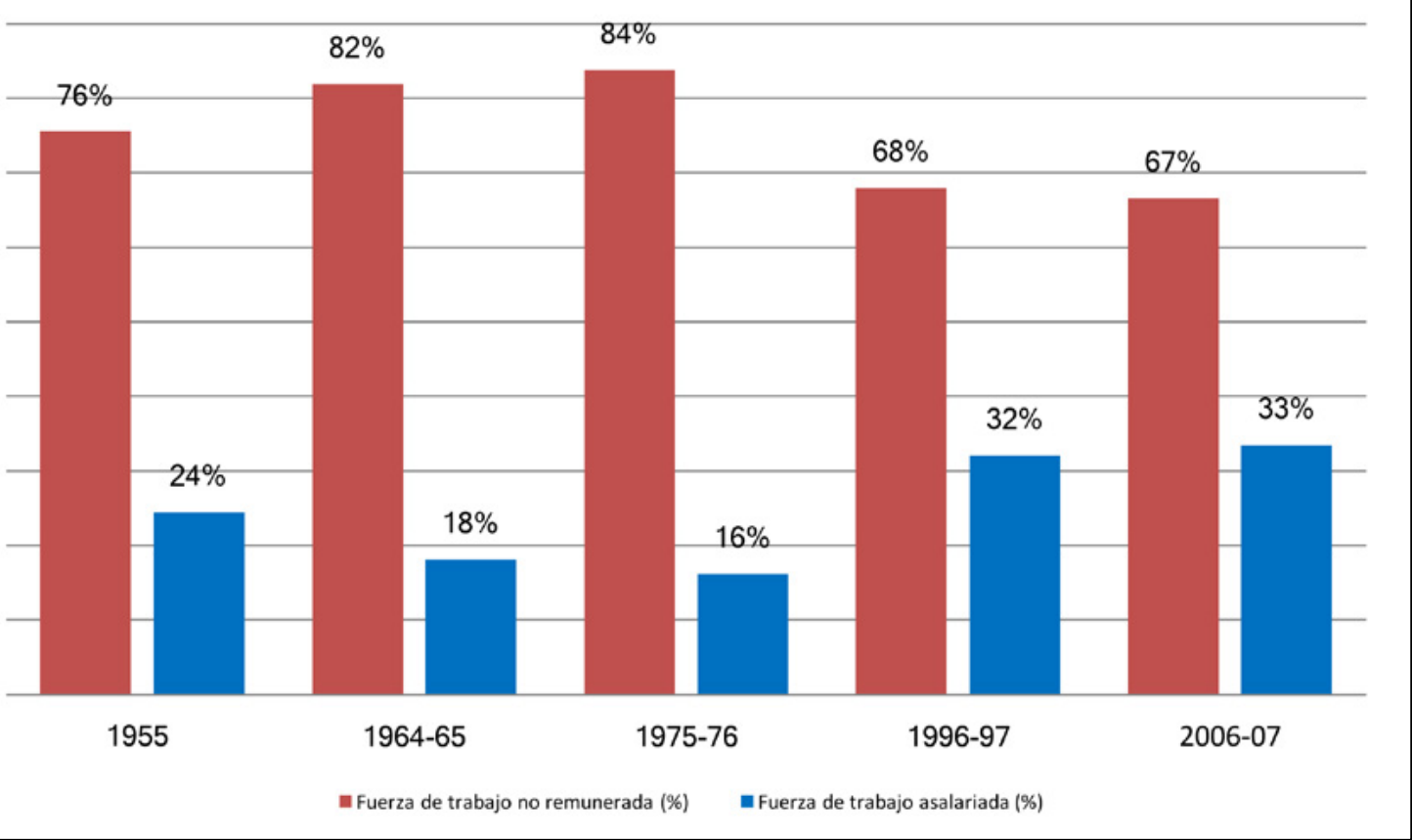

Figura 9. Carácter de la fuerza de trabajo agrícola en la provincia de El Loa (\%) (1955 a 2006-07). Fuente: Elaboración propia con datos del Servicio Nacional de Estadística y Censos (1955);

Dirección de Estadística y Censos (1969); INE (1980; s.f.-a; s.f.-b) y ODEPA (s.f.). 
cobre en la cuenca del Loa, cuyo ritmo se acelera durante la segunda mitad del siglo XX. El crecimiento urbano sigue la misma tendencia, al igual que las demandas de alimentos; específicamente, la demanda de carne en los mercados urbanos de Calama y Chuquicamata, razón por la cual hay mayor superficie sembrada con alfalfa para alimentar el ganado. En este período, la actividad agraria en el oasis de Calama es bastante fuerte (Figura 10) y explica en gran medida esta ampliación de la superficie agraria. Junto con ello, debe jugar algún rol la construcción por parte del Estado de un nuevo sistema de canalización entre 1960 y 1964 en San Pedro de Atacama (Rivera, 1995). Sin embargo, no hay referencias a un aumento en el dinamismo agropecuario con la fuerza que permitiría establecer un rol preponderante de San Pedro de Atacama en la ampliación de los cultivos de alfalfa, en la escala descrita. Es más, Rivera (1995), basado en una encuesta aplicada en el primer lustro de la década del noventa, señala que la estructura agraria de San Pedro de Atacama no sufrió mayores variaciones entre el estudio de Aranda (1961) y los primeros años de la década del noventa.
Por su parte, el aumento en la chacarería muestra una mayor participación de los agricultores de Chiu Chiu y Lasana en los mercados. Las entrevistas que hemos realizado mencionan que durante estos años existía venta de hortalizas y otros productos de chacarería a Chuquicamata por los agricultores de estas localidades. Se vendían a las pulperías del company town y los agricultores se coordinaban para que la mayoría pudiera participar en el mercado estableciendo turnos rotativos de venta. Los productos se llevaban en carretas y posteriormente en camiones. Los relatos etnográficos recopilados refieren que desde los ańos ochenta hay un auge de la producción mercantil de zanahorias en Chiu Chiu y Lasana. Al parecer las bases de esto empiezan a establecerse en esta etapa, como lo demuestran las 20 ha cultivadas en estos años en la provincia, constituyéndolo en el principal cultivo hortícola del período (Dirección de Estadística y Censos, 1969).

El fortalecimiento de la agricultura mercantil en Chiu Chiu y Lasana se desarrolla en paralelo a un proceso de proletarización hacia afuera del agro, con un componente importante de emigración definitiva o

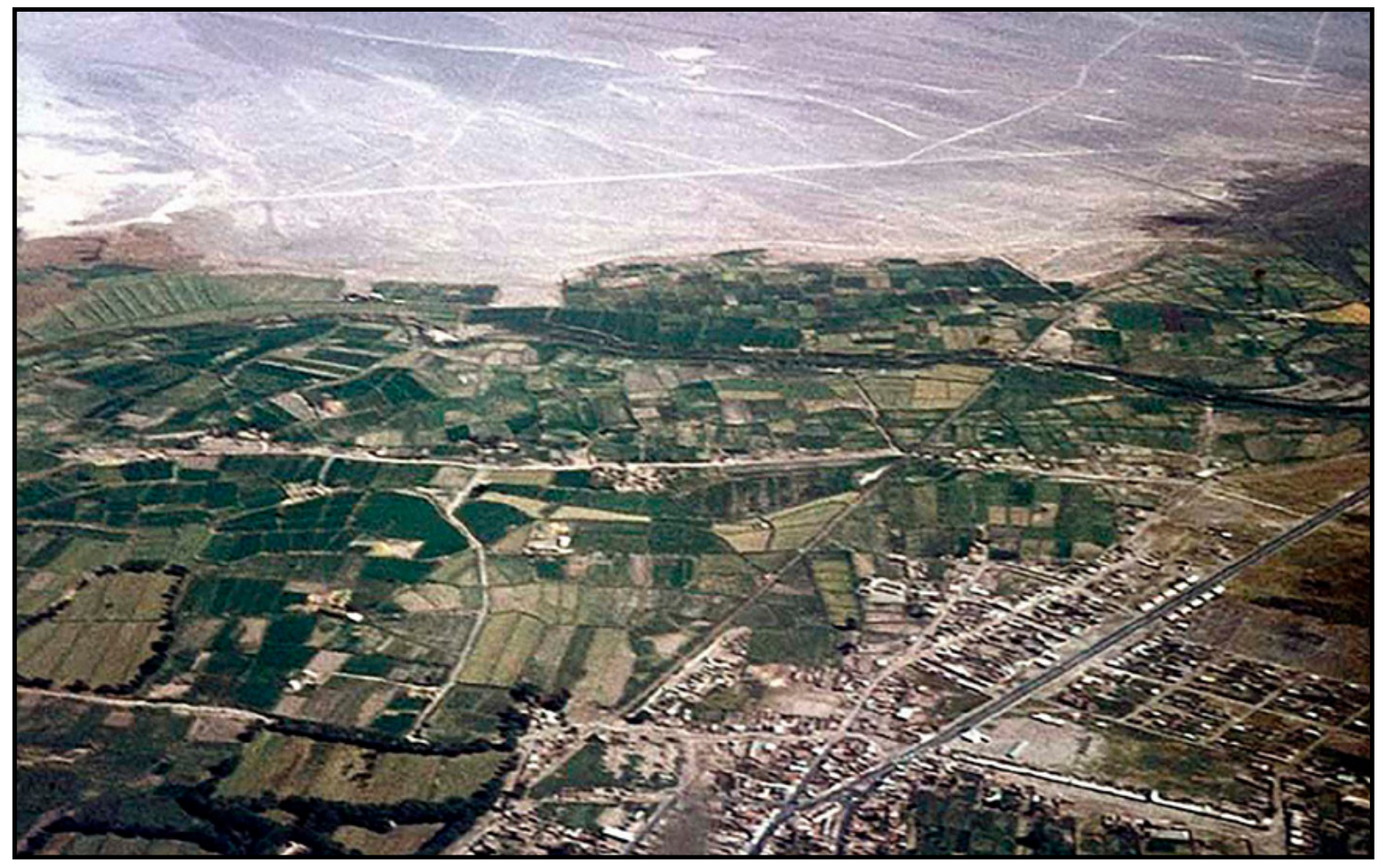

Figura 10. Vista aérea al oasis de Calama (1966). Fuente: Colección Museo Histórico Nacional (Anónima). 
estacional a Calama y Chuquicamata. De hecho, uno de los principales problemas que identifican algunos estudios para un desarrollo agrario más robusto está en la falta de fuerza de trabajo necesaria en determinados momentos (Beaulieu, 1967; Meneses, 1967).

El aumento de las hectáreas cultivadas por una agricultura de orientación mercantil va acompañado de un incremento de la fuerza de trabajo no remunerada. Los trabajadores totales del sector agrario aumentaron desde 1683 a 2373 ; de ellos, el $82 \%$ es no remunerado. Esto permite afirmar que en este período, la expansión de la agricultura comercial se sostuvo a base de relaciones de trabajo tradicionales que no implicaban un pago en salario.

Dentro de la fuerza de trabajo no remunerada se tiende a una mayor presencia masculina. Los hombres pasaron de representar el 55\% del total de trabajadores al 64\%, mientras que las mujeres disminuyen desde un $45 \%$ del total de trabajadores al $36 \%$. Ambos géneros aumentaron su presencia de modo absoluto, pero el incremento de hombres fue mucho más marcado (Servicio Nacional de Estadística y Censos, 1955; Dirección de Estadística y Censos, 1969). Esto estaría mostrando que la mercantilización de cierta agricultura demanda fuerza de trabajo masculina que, al menos por estos ańos, participa bajo vínculos tradicionales.

Los trabajadores asalariados prácticamente mantuvieron su número con un leve aumento de 18 personas, representando el $18 \%$ del total de la fuerza de trabajo. Lo relevante fue una reconfiguración de su composición interna. Mientras los trabajadores permanentes crecieron en 95 personas, los estacionales bajaron su contingente en 77 miembros. De este modo, el trabajo permanente pasó a representar el $44 \%$ del total del trabajo remunerado versus el $23 \%$ del censo anterior. No obstante, el trabajo asalariado sigue siendo preponderantemente temporal, con un $56 \%$ del total de trabajadores remunerados. Junto con ello, es relevante indicar que las mujeres participan menos en el mercado de trabajo agrícola, representando el $7 \%$ del total de trabajadores asalariados permanentes y el $1 \%$ del total de asalariados temporales.
Durante el período intercensal que nos lleva al año agrícola 1975-76, ocurre un debilitamiento de la agricultura de alfalfa de orientación comercial en Calama, donde están los terrenos más extensos. Este cultivo baja a nivel provincial desde 2439 a 1724 ha. Las causas son variadas: por una parte, a fines de la década del sesenta se pone en funcionamiento la Carretera Panamericana, con lo cual llegan productos agropecuarios de otros puntos del país y a menor precio. Estos empiezan a competir con la producción local, debilitando la actividad ganadera y los cultivos relacionados de alfalfa (Sanhueza y Gundermann, 2009). Junto con ello, la expansión de la ciudad de Calama, que había aumentado de 26 166 personas en 1960 a 45863 en 1970 (Dirección de Estadística y Censos, s.f.; INE, s.f.-c), genera una mayor presión sobre el suelo agrario por la expansión de la ciudad (Figura 11). Y, en tercer término, el desarrollo de la reforma agraria en el oasis afectó a los terrenos más grandes donde presumiblemente se concentraba la alfalfa, lo cual puede haber incidido en una reducción de la tierra destinada a este cultivo (Figura 12). ${ }^{22}$

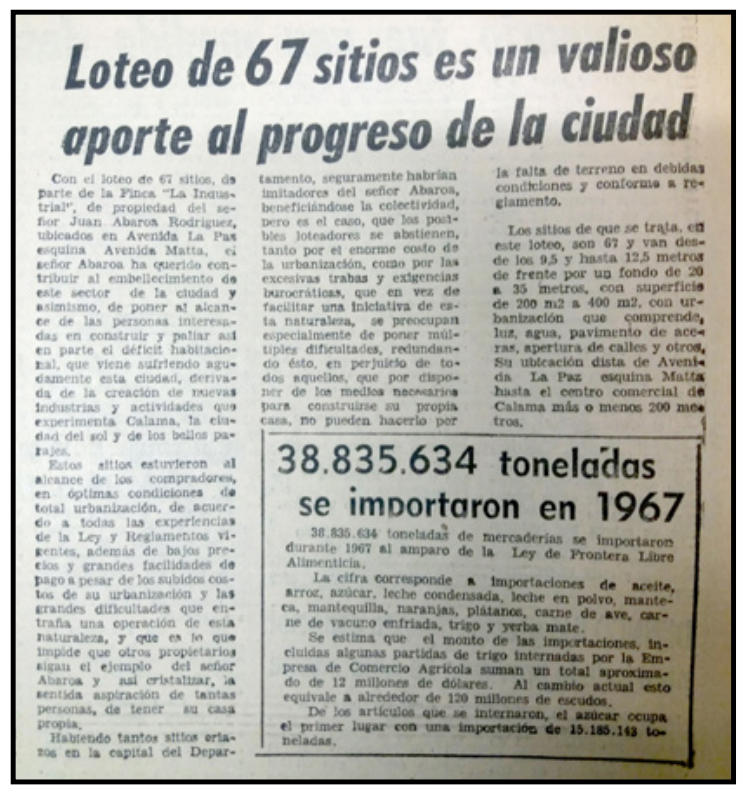

Figura 11. Noticia de loteo de sitios para expansión urbana Fuente: El Mercurio de Calama, 8 de febrero de 1968.

22 La suma de la extensión de seis de las ocho fincas expropiadas indicadas en la Figura 12 suman 1783 ha. 


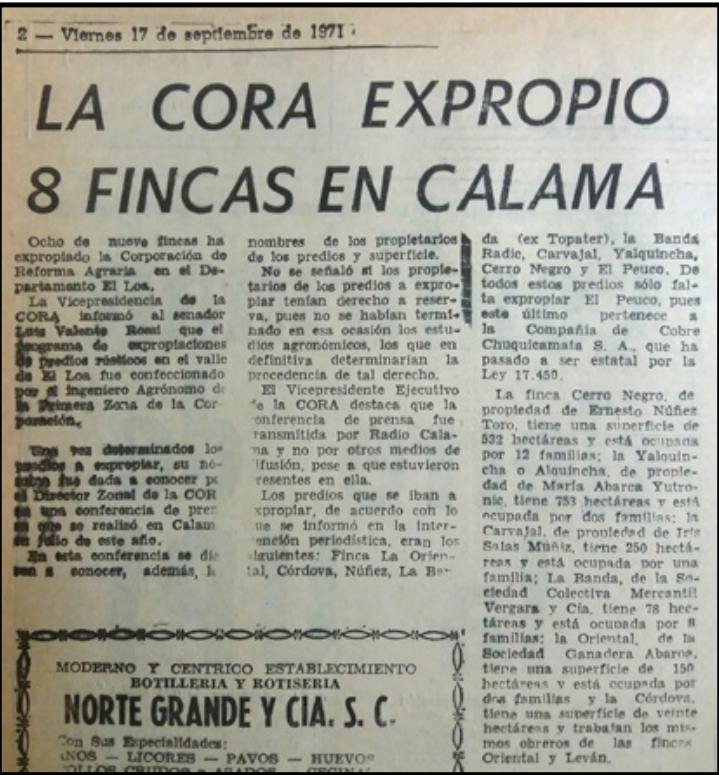

Figura 12. Noticia de expropiaciones de fundos en Calama Fuente: El Mercurio de Calama, 17 de septiembre de 1971.

De los otros cultivos, destaca el aumento de las hectáreas de trigo en poco más de 100 y la chacarería en cerca de 20. De las casi 20 ha que crece la chacarería, 16 corresponden a zanahorias. Como expusimos, hemos constatado etnográficamente que la chacarería se ha desarrollado principalmente en los sectores de Chiu Chiu y Lasana en el río Loa, presentando una fuerte orientación mercantil hasta la actualidad. ${ }^{23}$ A su vez que el trigo, que es un cultivo tradicional, en la actualidad ya no está presente, pero en los años anteriores era común encontrarlo en la generalidad de los poblados de la provincia, donde se destinaba al autoconsumo y se desarrollaba con fuerza de trabajo familiar y comunitario (trilla).

Estas variaciones de las actividades agrarias, tanto alfalfa, trigo y chacarería (zanahorias), implicaron un aumento en la fuerza de trabajo del agro desde 2373 a 2988 individuos, explicada por la mayor participación de personas mediante relaciones tradicionales no remuneradas, las que aumentan sobre las 500

23 Durante esta década empiezan a llegar familias aymaras del norte de Chile, que se instalan en Chiu Chiu comprando tierras y fortaleciendo la actividad agrícola mercantil. Tienen presencia hasta la actualidad. personas. Los no remunerados pasan a ser el $84 \%$ del total de trabajadores del sector, donde hombres y mujeres se incorporan en magnitud similar, manteniendo una distribución entre géneros como en el censo previo.

Por su parte, el trabajo asalariado también aumenta, pero en menor magnitud que el anterior, llegando al $16 \%$ del total de trabajadores (18\% en censo previo). El principal incremento está en los asalariados permanentes, que suben en casi 90 personas. Esto, junto con la baja del trabajo asalariado temporal, conlleva que la estructura de empleo remunerado sea ahora predominantemente estable, con un 57\% del total de asalariados. Existe en este período una importante incorporación de mujeres al mercado de trabajo agrario, ahora un $24 \%$ de trabajadoras respecto del total de asalariados permanentes $(7 \%$ censo anterior) y $10 \%$ de los temporales ( $1 \%$ censo anterior).

Esto permite establecer que, primero, la alfalfa tiene escaso impacto en el uso de la fuerza de trabajo en el sector agrario de la zona, ya que una baja de alrededor de 1000 ha no afecta el número de trabajadores, los cuales incluso aumentan. En segundo lugar, que la agricultura mercantil que se desarrolla a base de las zanahorias hace uso de empleo asalariado permanente en conjunto con trabajo no remunerado, configurando un campesino semicapitalista en cuanto contrata fuerza de trabajo externa. $\mathrm{Y}$, en tercer término, que el aumento de las siembras de trigo, como producto tradicional, se ejecuta con trabajo familiar y comunitario no remunerado. Los datos etnográficos que hemos recopilado van en esta línea. Se nos ha informado que los cultivos que efectivamente son intensivos en empleo de mano de obra son las hortalizas y no la alfalfa.

En resumen, el trabajo bajo vínculos no salariales nos revela un mecanismo laboral de alta relevancia en las transformaciones agrarias del territorio, que ha operado según contextos para fortalecer una agricultura capitalizada, al campesinado mercantil o campesinado de autoconsumo.

En la década del ochenta no se realizó censo agropecuario en Chile, por lo tanto, para dar cuenta de algunos aspectos claves de la dinámica agraria, nos 
basaremos en el estudio de Consecol (1988). ${ }^{24} \mathrm{Tal}$ como se observa en la Figura 4, la estructura de cultivo se mantiene en porcentajes similares a lo observado en la década anterior, cuando la alfalfa representa el 64\% del total de hectáreas agrícolas; el maíz, el $16 \%$; el trigo, el $14 \%$, y la chacarería, un $3 \%$.

Datos de Consecol (1988) sobre el destino de la producción confirman, tal como lo indicamos, que esta configuración de uso de la tierra implica que las localidades agrícolas ubicadas en la cuenca del río Loa, principalmente las más cercanas a los centros urbanos, tienen una mayor articulación mercantil en comparación a las emplazadas en el salar de Atacama; espacio donde se viene experimentado desde hace décadas una desarticulación de los mercados de la actividad agraria. En la cuenca del río Loa se destaca el destino mercantil de la agricultura en Chiu Chiu, donde el $91 \%$ del total de la producción agraria va al mercado. También destaca Caspana con el $80 \%$ y Toconce con el $74 \%$. En la agricultura de Calama, debido a los procesos ya referidos de debilitamiento de las articulaciones mercantiles del agro, se vende el $64 \%$ del total de la producción agrícola del oasis. Contrariamente, están los poblados del salar de Atacama, donde las localidades orientan sobre el $80 \%$ de la producción agrícola al autoconsumo, destacando Peine y Talabre donde todo se consume localmente.

Durante la década del ochenta ya se han constatado las dinámicas de movilidad (con distintas permanencias) desde las localidades rurales de la provincia hacia Calama y Chuquicamata. Por lo tanto, a nivel general de la población indígena, las principales fuentes de ingresos ya se sustentan en actividades desarrolladas en las urbes, junto con la minería (Bähr, 1985). Sin embargo, para la población que se mantiene en las localidades rurales, las actividades agropecuarias siguen representando sobre el 50\% del total de sus ingresos. Lo cual, de todos modos, da cuenta de una participación relevante de las ocupaciones no agrícolas en la población rural (Consecol, 1988).

24 El estudio no es de carácter censal, sino que trabajó mediante muestras. Por ello sus datos son referenciales pero no comparables en sentido estricto con los censos.
Durante esta década se implementa el Código de Aguas de 1981 en la cuenca del río Loa. Si bien el despojo de sus aguas se presenta a lo largo de todo el siglo XX, esta normativa lo agudiza (Yáñez y Molina, 2011). Sobresalen algunas dinámicas de escala subprovincial, por ejemplo, el desecamiento del río San Pedro de Inacaliri (Cavieres, 1985), despojo de agua en Toconce y desecamiento de humedales (González, 1999), y desecamiento de parte de las vegas de Chiu Chiu (Prieto, 2015). Actualmente, la actividad ganadera en el río San Pedro de Inacaliri ha desaparecido, lo mismo en los humedales del sector de Toconce, mientras que su agricultura se ha visto fuertemente mermada. Por su parte, en Chiu Chiu se mantiene una agricultura articulada a mercados. Empero, se afectó la capacidad de sostener ganado y por ello de acceder autónomamente a abono animal. Según constatamos en terreno, su consecuencia fue una mayor dependencia de químicos y compra de abono animal.

En el año agrícola 1996-97, luego de décadas, hubo un cambio en los principales cultivos, situación que se vincula a nuevas relaciones mercantiles en torno a la chacarería (específicamente hortalizas) y el maíz choclo. La alfalfa mantiene su participación con el $68 \%$ del total del uso de suelo, luego el maíz con $15 \%$, mientras que el tercer lugar ahora lo ocupa la chacarería, con un 9,5\% (en el censo anterior era el $3 \%)$. El trigo comprendió el 2,7\% del total del uso del suelo agrícola, incluso por detrás de frutales $\mathrm{y}$ viñas (4,6\%) (INE, 1980; s/f-a).

El dato del maíz debe profundizarse. Si en el censo anterior su composición interna era similar entre maíz grano y maíz choclo (139 y 187 ha, respectivamente), en esta década el choclo comprende prácticamente la totalidad de la producción (406 ha versus 11 ha). Según la información etnográfica que hemos registrado, el maíz grano históricamente se orientó al autoconsumo e intercambio recíproco, mientras que el maíz choclo más hacia el mercado. Actualmente el choclo es uno de los principales cultivos en Calama, el cual se destina en gran medida al mercado, como también su producción en otros poblados de la cuenca del río Loa como Chiu Chiu y Lasana. 
El caso de la chacarería es también necesario detallarlo. Siguiendo nuestros datos etnográficos, desde fines de la década del ochenta, se experimentó un "boom" del cultivo de zanahorias para venta, principalmente en Chiu Chiu (aunque también en Lasana). Este fenómeno se manifiesta en el aumento de la chacarería, llegando a un total de 260 ha, de las cuales 124 son de zanahorias (INE, s.f.-a).

Durante la década del noventa, Gundermann y González (1995) constataron para la zona del salar de Atacama, la presencia de diversos cultivos tales como alfalfa, maíz, trigo, hortalizas y frutas (membrillos y peras) con diferente presencia dependiendo de la localidad. Estos cultivos, desarrollados con fuerza de trabajo doméstica, eran destinados principalmente al autoconsumo y ocasionalmente al mercado. Se plantea que las unidades domésticas rurales se encuentran en un estado en que pueden sostenerse de la actividad agropecuaria de modo precario, solo desarrollando venta de fuerza de trabajo. Observan diferenciación campesina hacia la proletarización, sin presencia de unidades semicapitalistas.

En este censo se vuelve a identificar un aumento en los trabajadores agrícolas, pero a diferencia de los censos anteriores, en este caso, los que se incrementan son los asalariados. En consideración a las características agrarias descritas para las zonas del río Loa y salar de Atacama, la presencia de ellos debió concentrarse en torno al cultivo de zanahorias en Chiu Chiu y Lasana, actividad que en esos años pasaba por su mayor auge.

De todos modos, tanto remunerados como no remunerados crecieron, pero los primeros tuvieron un incremento mucho mayor. Subieron de representar el $16 \%$ al $32 \%$ del total de la fuerza de trabajo, mientras que los no remunerados descendieron desde el 84 al 68\% del total de trabajadores agrícolas. Las mujeres se incorporan más rápidamente como trabajadoras no remuneradas que los hombres; estos último aumentan su participación, pero a ritmo menor. Es así que las mujeres pasan desde el 37 al 41\% del total de los trabajadores no remunerados.

Aunque gran parte de la actividad agrícola de la provincia se seguía sosteniendo sobre la base de las relaciones tradicionales, que no implican remuneración, en Chiu Chiu se evidencia un polo más dinámico que gatilla mayor presencia de asalariados en el área de estudio. Es importante añadir que, de acuerdo a la información de terreno, quienes se emplean como asalariados en el agro son personas de la misma zona de estudio que se movilizan por el territorio, como también trabajadores que llegan desde el sur de Bolivia.

Dentro del trabajo asalariado, se revierte la composición entre temporales y permanentes. Antes los permanentes eran mayoría, pero el auge de las zanahorias y otras hortalizas de orientación de mercado se sostiene sobre la base del empleo temporal. Este pasa desde el $43 \%$ del total de fuerza de trabajo asalariada al 66\%, mientras que el permanente disminuye desde el $57 \%$ del total de la fuerza de trabajo remunerada al $34 \%$.

El año agrícola 2006-2007 (INE, s.f.-b), identificamos por primera vez una reducción general de todos los cultivos en el área de estudio. El maíz bajó aproximadamente en 100 ha; el trigo, en 50; la alfalfa, en 800, y la chacarería, en 60. Empero, la estructura de cultivos mantuvo su conformación anterior: $65 \%$ del total del uso de suelo agrícola fue en alfalfa, 19\% en maíz y $10 \%$ en chacarería.

Al profundizar en las cifras según comuna, vemos que la mayor extensión de alfalfa está en San Pedro de Atacama, doblando a Calama (749 y 335 ha, respectivamente). Según Gundermann y González (1995), es un uso del suelo que se mantiene debido a la costumbre, como también a que no demanda mucha fuerza de trabajo, pero no porque exista una articulación al mercado dinámica como lo era en el pasado. Por su parte, en los restantes cultivos, Calama duplica la superficie de San Pedro de Atacama. ${ }^{25}$ Esto vuelve a confirmar que la dinámica agraria de ambos sectores es heterogénea, con presencia de autoconsumo y agricultura de mercado; pero en sectores de la comuna de Calama, se ha configurado una actividad agrícola con articulaciones más dinámicas a los mercados, dando forma a unidades semicapitalistas, con demanda de trabajo asalariado. Mientras que en la comuna de San Pedro de Atacama, hay

25 Por ejemplo, en cereales, leguminosas y tubérculos Calama posee 132 ha y San Pedro de Atacama, 56; en hortalizas Calama tiene 208 ha y San Pedro de Atacama, 123. 
mayormente una agricultura de autoconsumo con menor articulación con los mercados y sin presencia de trabajo asalariado. No obstante, en ambos sectores, las fuentes de ingreso de las unidades domésticas indígenas provienen principalmente de la minería y empleos urbanos, tanto como asalariados o cuentapropistas (Gundermann, 2013).

Recordemos que desde 1955 evidenciamos un aumento de los trabajadores que participan en las actividades agrarias, más allá de las variaciones en la modalidad en que se involucran. Esta tendencia al alza se revierte en este último período. De 4023 trabajadores se pasa a 3705. La dinámica de la fuerza de trabajo está determinada por la evolución de la chacarería y el cultivo del maíz, en cuanto son las principales actividades que hacen uso intensivo de ella.

Otro aspecto que constatamos en este período, y que marca una diferencia en el comportamiento histórico, es que la principal disminución de trabajadores corresponde a los no remunerados, mientras que los asalariados, aunque descienden, muestran un decrecimiento menor. De todas formas, la participación de cada tipo se mantiene porcentualmente. Un $67 \%$ del total de fuerza de trabajo es no remunerado y un 33\%, remunerado. Junto con constatar el cambio de tendencia, destacamos que la actividad sigue sosteniéndose principalmente en relaciones tradicionales, pero hay cada vez más presencia de vínculos salariales.

Dentro de la fuerza de trabajo no remunerada, la composición de acuerdo a género muestra otro cambio relevante. La mayor presencia femenina que se detectaba en el período previo se consolida (dentro del total de trabajadores no remunerados hay paridad de 50\% entre hombres y mujeres). Mientras que los hombres se retiran de la esfera tradicional (lo cual explica su descenso total), son las mujeres las que se incorporan reinyectando fuerza a la actividad agraria (INE, s.f.-a; s.f.-b).

Dentro de los trabajadores asalariados, los permanentes disminuyen mientras que los estacionales se mantienen. Los estables pasan a representar un 30\% del total de trabajadores remunerados, mientras que los estacionales, un $70 \%$.
Identificamos para este período una estructura agraria con tendencias que dan cuenta de un debilitamiento mayor en las décadas recientes, lo que ocurre en un contexto de desagrarización del ingreso de las unidades domésticas por la minería del cobre, minería de altura, empleos urbanos y, en décadas recientes, minería de litio y turismo. Esto a pesar de la existencia de localidades en el río Loa con mayor dinamismo, como son Chiu Chiu y en menor medida Lasana (Figuras 13 y 14). Sin embargo, en estos propios lugares, el empleo en trabajos no agrícolas como asalariado o cuenta propia es común y resta al agro mano de obra necesaria, la cual es cubierta gracias a la llegada de trabajadores del sur de Bolivia. Según vimos en terreno, se insertan principalmente como asalariados por jornal y temporeros, y en menor medida como campesinos medieros y arrendatarios.

Finalmente, creemos necesario mencionar las políticas públicas de fomento agrario como un componente que incide en la reproducción de la actividad en el presente (al menos desde la década del noventa). Desde entonces, los organismos intensifican su presencia en el territorio, luego de cierto alejamiento durante la década del ochenta, según la propia opinión de los agricultores entrevistados. ${ }^{26}$ Más allá de la evaluación de los proyectos específicos, destacamos al Instituto de Desarrollo Agropecuario (fomento de invernaderos, apoyo en insumos y maquinaria, revestimiento de canales y fomento de actividades rurales no agrícolas), al Servicio Agrícola y Ganadero (recuperación de suelos y sanitización animal), la Corporación Nacional Forestal (entrega de árboles frutales), la Comisión Nacional de Riego (revestimiento de canales) y la Corporación $\mathrm{Na}-$ cional de Desarrollo Indígena (apoyo en obras de riego), por nombrar a los servicios que vimos con mayor presencia en terreno.

El último censo analizado corresponde al año agrícola 2006-07; en consecuencia, solo una comparación con cifras actualizadas con el futuro censo del 2021 nos permitirá establecer si estas dinámicas son efectivamente una precarización que se agudiza o un ciclo de decaimiento dentro de diversos momentos

26 Algunos lo vinculan a la promulgación de la Ley Indígena en 1993 (Ley 19.253). 


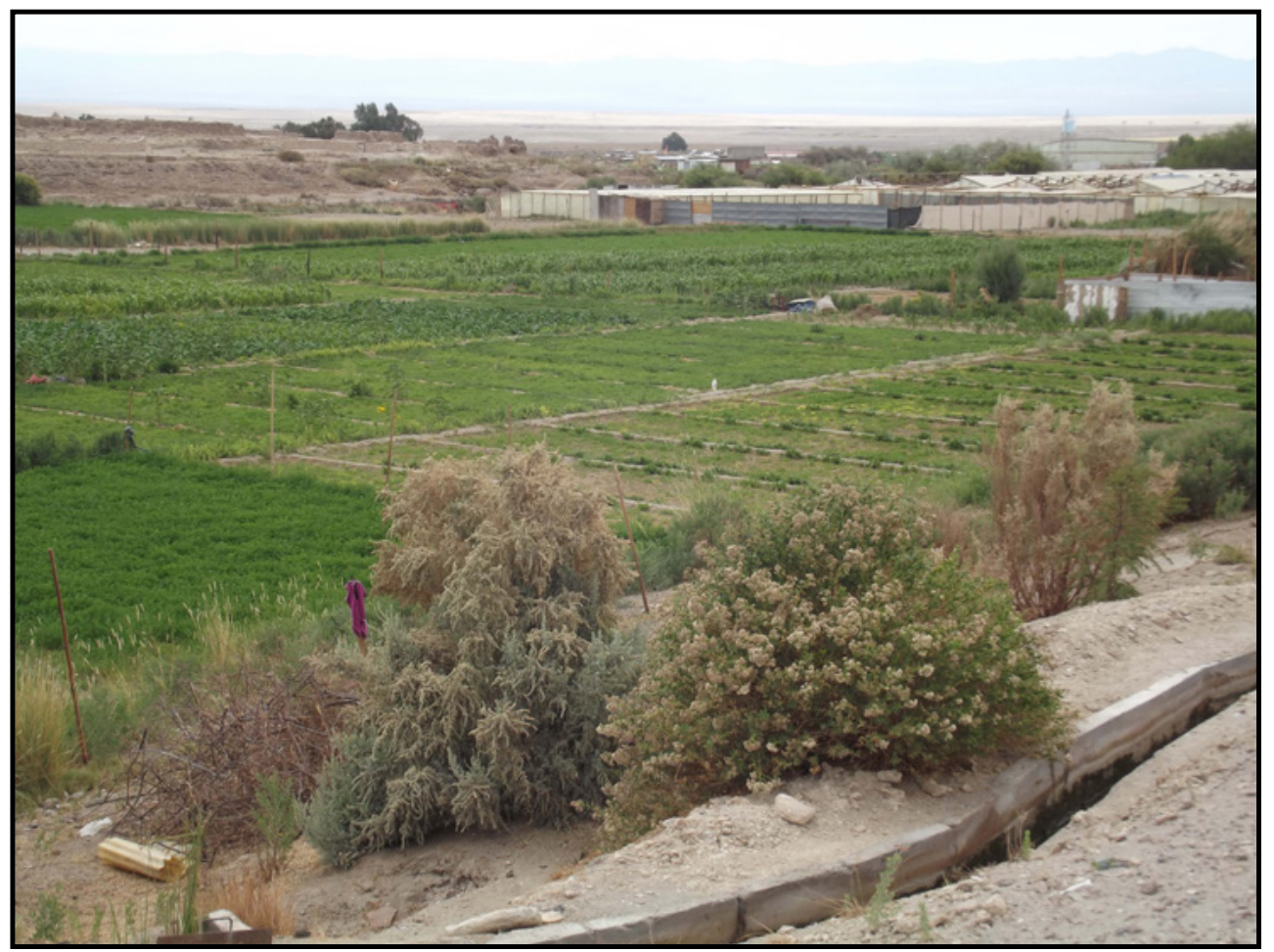

Figura 13. Cultivos en Chiu Chiu (2018). Fuente: Registro de Matías Calderón.

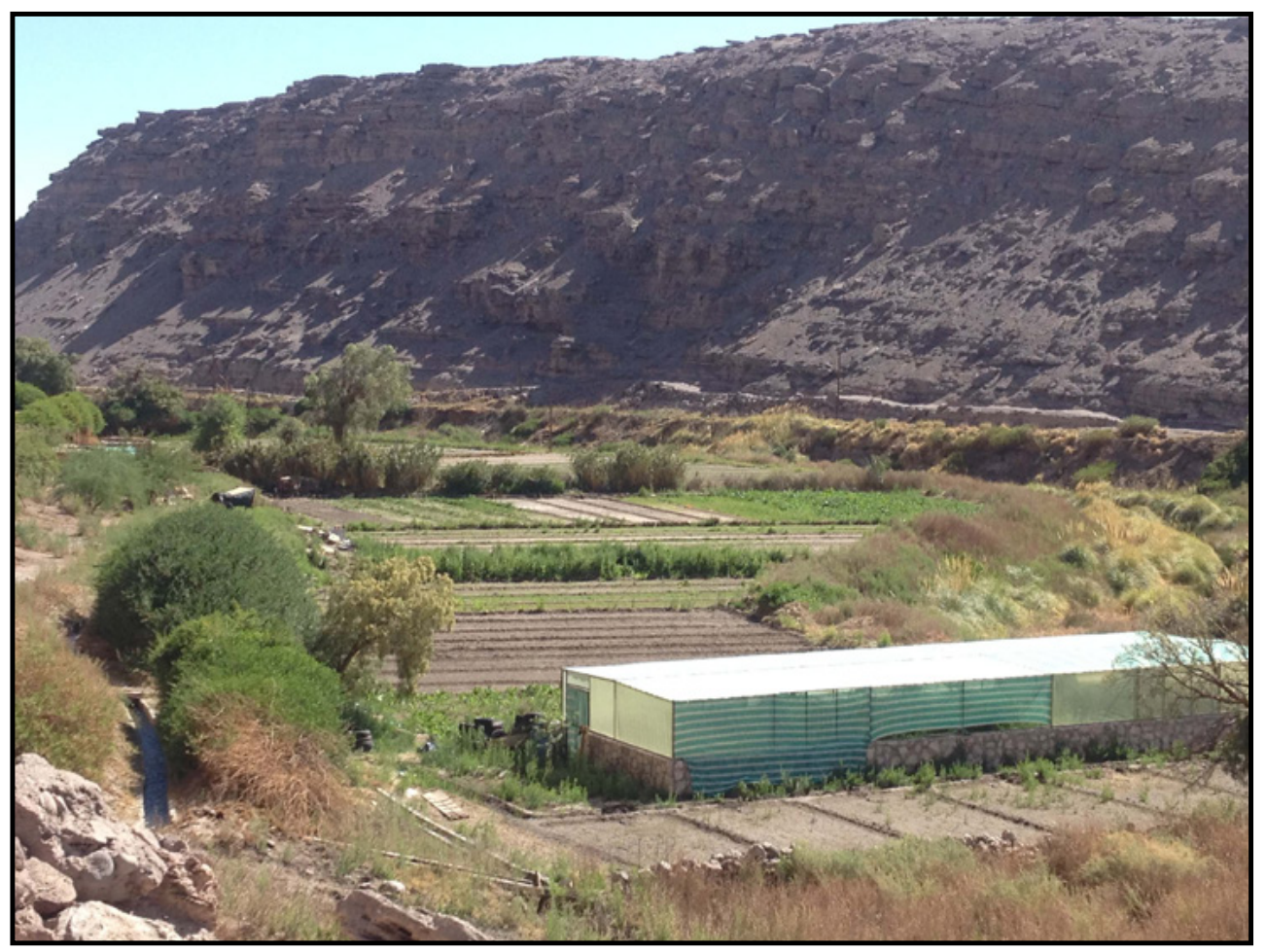

Figura 14. Cultivos Lasana (2018). Fuente: Registro de Matías Calderón. 
de fortalecimiento y fragilidad de la actividad agraria a lo largo del período revisado. Momentos que, tanto en sus estados expansivos como regresivos, han estado determinados por el extractivismo y sus procesos relacionados.

\section{Comentarios finales}

Hemos analizado la cuestión agraria en la provincia de El Loa durante el siglo XX y XXI, dando cuenta de cómo su desarrollo solo puede comprenderse en relación a la expansión del extractivismo cuprífero. Aspectos de niveles menores al provincial, como puede ser el de cuencas o localidades, fueron especificados cuando eran de relevancia para entender la dinámica más amplia.

Procesos claves de la cuestión agraria, como son la separación de parte de la propiedad de la tierra del campesinado indígena, dinámicas de proletarización de variable intensidad o la participación en formas de ingreso monetario, no emergen con la llegada del extractivismo cuprífero. La presencia de este capital agudiza estas dinámicas e, incluso, impulsa nuevos aspectos. Sin embargo, la cuestión agraria en estos términos es anterior y se vincula a otros capitales extractivos en los Andes centro-sur; como los de la minería del sur de Bolivia y la minería de salitre en el norte de Chile. En este sentido, aspectos fundantes de la cuestión agraria relacionados a la acumulación originaria y despojo de la tierra son anteriores al cobre. Sin embargo, se expande y agudiza en el período cuprífero con otros recursos del territorio, como las aguas.

La actividad cuprífera no determina homogénea ni unidireccionalmente al agro. Los datos dan cuenta de cambiantes formas de conexión, subordinación y contradicción. A veces fomentando una crisis, otra una expansión, como ambas simultáneamente dependiendo de qué aspectos observemos y dónde. En este sentido, la cuestión agraria se produce con heterogeneidad histórica y espacial.

La heterogeneidad histórica apunta a que los distintos ciclos de expansión y debilitamiento del extractivismo generan diferentes formas (en movimiento) de la cuestión agraria. Pueden fortalecer a una agricultura capitalista, un campesinado semiproletario mercantil o de autoconsumo, un campesinado semicapitalista mercantil o una proletarización avanzada.

Las dinámicas de diferenciación campesina se presentan dentro de la misma actividad agraria en determinados momentos, pero principalmente y en continuidad histórica, hacia la minería (en sus distintas formas), industria y empleos urbanos. Esto, desde tiempos anteriores al cobre, comprende diversas prácticas de movilidad estacional y definitiva a lo largo del territorio. Igualmente, la diferenciación y proletarización en este territorio extractivo se acompaña puntualmente de despojo de la propiedad de la tierra (donde penetra efectivamente el capital agrario), pero en las zonas donde este queda al margen, predomina la pequeña propiedad campesina. Sin embargo, debido a otras dinámicas asociadas al extractivismo, la diferenciación, proletarización y desagrarización de los ingresos ocurren igualmente.

Por su parte, la heterogeneidad espacial refiere a que, en un mismo momento, habrá formas diferenciadas de la cuestión agraria en los distintos espacios de la provincia, dependiendo de su ubicación respecto de la circulación de mercancías, los puntos de extracción de minerales y aguas, los centros urbanos, pisos ecológicos, de los usos tradicionales de ellos y por el surgimiento de nuevos procesos complementarios (p.e., litio y turismo en San Pedro de Atacama). Estos elementos modelan sincrónicamente la diversidad del sistema agrario, lo intensifican y debilitan, estableciendo una relación dinámica entre estas poblaciones, sus prácticas económicas y los ciclos de expansión capitalista.

A su vez, tanto en su perspectiva diacrónica como sincrónica, la forma en que se despliega el Estado es un componente a considerar para analizar la cuestión agraria, tanto en sus debilitamientos como, a veces, su sostenimiento. Por ejemplo, fomentando la actividad cuprífera, favoreciendo el crecimiento urbano, avalando formas privadas y mercantiles de gestión de las aguas, desarrollando infraestructura que hace que lleguen productos de otras zonas con los cuales la producción local no puede competir, como también, impulsando obras de riego, inserción de nuevos cultivos, técnicas de producción, entre otros. 
En síntesis, en un territorio donde el principal gran capital que opera es extractivo-minero y no agrario, el primero configurará la cuestión agraria en general y la situación del campesinado en particular, mediante mecanismos similares, pero no idénticos, a los que ocurren en espacios donde el gran capital es el agropecuario. Las tendencias generales al debilitamiento de la economía campesina, su diferenciación y proletarización acontecen, pero mediante formas distintas.

\section{Agradecimientos}

Agradecemos a los proyectos FONDAP 15110006; FONDECYT 11150130, 1181859, 1160848 у Pro-Fondecyt 2019 - Universidad Católica del Norte. Matías Calderón agradece a CONICYT PFCHA/Doctorado Nacional 2019-21190475, por financiar sus estudios doctorales. También nuestros reconocimientos a los informantes entrevistados en terreno, a Gino Sandoval por elaborar la cartografía, a Hans Gundermann y Tom Perreault por leer y comentar versiones previas del artículo, y finalmente, a los evaluadores anónimos por sus observaciones.

\section{Referencias citadas}

Acosta, A. (2016). Las dependencias del extractivismo. Aporte para un debate incompleto. Actuel Marx Intervenciones, 20, 123-154.

Aldunate, C. (1985). Desecación de las Vegas de Turi. Chungará, 14, 135-139.

Aldunate, C., Berenguer, J., Castro, V., Cornejo, L., Martínez, J., Sinclaire, C. (1986). Cronología y asentamiento en la región del Loa Superior. Santiago: Dirección de Investigación y Bibliotecas, Universidad de Chile.

Alimonda, H. (Coord.). (2011). La naturaleza colonizada. Ecología política y minería en América Latina. Buenos Aires: CICCUS/CLACSO.

Aranda, X. (1961). San Pedro de Atacama. Elementos diagnósticos para un plan de desarrollo local. Investigaciones Geográficas, 11-14, 19-61.

Arrau Ingeniería E.I.R.L. (2012). Diagnóstico Plan Estratégico para la gestión de los recursos hidricos Región de Anto- fagasta. Informe Final, Volumen 2. S.I.T. N²91, DGA: Santiago.

Arroyo, A. y Boelens, R. (Eds.). (2013). Aguas robadas. Despojo hidrico y movilización social. Lima: IEP / Quito: Abya-Yala.

Bähr, J. (1985). Agriculture, Copper Mining, and Migration in the Andean Cordillera of Northern Chile. Mountain Research and Development, 5(3), 279-290.

Banco Central. (s.f.). Base de datos estadisticos. http://si3. bcentral.cl/Siete/secure/cuadros/home.aspx [Consulta: 18.08.2017].

Barros, A. (2008). Identidades y propiedades: transiciones territoriales en el siglo XIX atacameño. Estudios Atacameños. Arqueología y Antropología Surandinas, 35, 119-139.

Barthel, T. (1986). El agua y el festival de primavera entre los atacameños. Allpanchis, 28, XVIII(2), 147-184.

Beaulieu, A. (1967). El hábitat humano y la economía agrícola en el oasis de Chiu-Chiu. Revista de la Universidad del Norte, 4, 81-101.

Bebbington, A. (Ed.). (2007). Minería, movimientos sociales y respuestas campesinas: una ecología politica de transformaciones territoriales. Lima: IEP - CEPES.

Bebbington, A. (Ed.). (2012). Social conflict, Economic Development and Extractive Industry. Nueva York: Routledge.

Bebbington, A. y Bury, J. (Eds.). (2013). Subterranean struggles: new dynamics of mining, oil, and gas in Latin America. Austin: University Texas Press.

Bengoa, J. (2003). 25 años de estudios rurales. Sociologías, 5(10), 36-98.

Bolados, P. (2014). Los conflictos etnoambientales de "Pampa Colorada" y "El Tatio" en el salar de Atacama, norte de Chile. Procesos étnicos en un contexto minero y turístico transnacional. Estudios Atacameños. Arqueología y Antropologia Surandinas, 48, 229-248.

Bowman, I. (1942). Los senderos del desierto de Atacama. Santiago: Sociedad Chilena de Historia y Geografía.

Calderón, M., Benavides, C., Carmona, J., Gálvez, D., Malebrán, N., Rodríguez, M. ... Urzúa, J. (2016). Gran 
minería y localidades agrícolas en el norte de Chile: comparación exploratoria de tres casos. Chungara. Revista de Antropología Chilena, 48(2), 295-305.

Calderón, M. y Prieto, M. (2019). Distribución y evolución de los Derechos de Aprovechamiento de Aguas otorgados por el Estado en la Región de Antofagasta (1905-2018). Informe preparado para el proyecto Fondecyt Regular 1181859.

Carmona, J. (2016). Minería industrial y estructuras agrarias "locales" en el Desierto de Atacama. Genealogía de una crisis agrícola (Quillagua, s. XIX-XXI). Estudios Atacameños. Arqueología y Antropología Surandinas, 52, 91-112.

Carrasco, A. (2014). Entre dos aguas: identidad moral en la relación entre corporaciones mineras y la comunidad indígena de Toconce en el desierto de Atacama. Chungara. Revista de Antropología Chilena, 46(2), 247-258.

Carrasco, A. (2016). A Biography of Water in Atacama, Chile: Two Indigenous Community Responses to the Extractive Encroachments of Mining. Journal of Latin American and Caribbean Anthropology, 21(1), 130-150.

Carrasco, A. y Fernández, E. (2009). Estrategias de resistencia indígena frente al desarrollo minero. La comunidad de Likantatay ante un posible traslado forzoso. Estudios Atacameños. Arqueología y Antropología Surandinas, 38, 75-92.

Castro, V. (2016). Etnoarqueologías andinas. Santiago: Ediciones Alberto Hurtado.

Castro, V. y Martínez, J. L. (1996). Poblaciones indígenas de Atacama. En Hidalgo, J., Schiappacasse, V., Niemeyer, H., Aldunate, C. y Mege, P. (Eds.). Culturas de Chile. Etnografía. Sociedades indigenas contemporáneas y su ideologia (pp. 69-109). Santiago: Andrés Bello.

Cavieres, A. (1985). Informe Final proyecto W.U.S.- A.H.C. Estudio del efecto de las politicas de uso de los recursos hidricos del altiplano chileno sobre las comunidades de pastores aymaras. Santiago: CODEFF.

Comisión Central del Censo (s.f.). Memoria presentada al Supremo Gobierno por la Comisión Central del Censo de 1907. S.i.

Comisión Chilena del Cobre (s.f.). Estadisticas de Producción Minera. https://www.cochilco.cl/Paginas/Estadisticas/
Bases\%20de\%20Datos/Producci\%C3\%B3n-Minera. aspx. [Consulta: 18.08.2017].

Consecol (1988). Diagnóstico agrícola Provincia de El Loa, II Región. Informe Final (2 tomos). S.i.: Consecol.

Contreras, C. (1988). Mineros y campesinos en los Andes. Mercado laboral y economía campesina en la Sierra Central. Siglo XIX. Lima: IEP.

Cuadra, M. (2000). Teoría y práctica de los derechos ancestrales de agua de las comunidades atacameñas. Estudios Atacameños, 19, 93-112.

Délano, P. (1982). Aspectos socioeconómicos de una comunidad del Norte Grande: Caspana. Tesis de Licenciatura. Universidad de Chile, Santiago.

Delgado, G. (Coord.). (2013). Ecología politica del extractivismo en América Latina: casos de resistencia y justicia socioambiental. Buenos Aires: Clacso.

Dirección de Estadística y Censos. (s.f.). Censo de Población 1960. Entidades de Población. Antofagasta. s.i.: Dirección de Estadística y Censos.

Dirección de Estadística y Censos. (1969). IV Censo Nacional Agropecuario. Año Agrícola 1964-1965. Tomo 3, Antofagasta. Santiago: Dirección de Estadística y Censos.

Dirección General de Estadística. (1925). Censo de Población de la República de Chile. Levantado el 15 de diciembre de 1920. Santiago: Dirección General de Estadística.

Dirección General de Estadística. (1933). Censo Agropecuario 1929-30. Santiago: Dirección General de Estadística.

Dirección General de Estadística. (1938). Censo Agricultura 1935-36. Santiago: Dirección General de Estadística.

Engels, F. (s.f.). "El problema campesino en Francia y Alemania”. En Marx, K. y Engels, F. Obras Escogidas (pp. 654-673). Moscú: Editorial Progreso.

Fernandes, B. (2014). Cuando la agricultura familiar es campesina. En Hidalgo, F., Houtart, F. y Lizárraga, P. (Eds.). Agriculturas campesinas en Latinoamérica. Propuestas y desafíos (pp. 19-34). Quito: Editorial IAEN.

Folla, J. (1989). Anthropologie économique d'une communauté paysanne du désert d'Atacama: Socaire. Tesis de Maestría. Universidad de Montreal, Montreal. 
Fundación Chile (1993). Diagnóstico del uso y evaluación de los recursos suelo, clima y agua en comunidades étnicas de la Provincia de El Loa. Santiago: Fundación Chile Codelco.

Göbel, B. y Ulloa, A. (Eds.). (2014). Extractivismo minero en Colombia y América Latina. Bogotá: Universidad Nacional de Colombia / Berlín: Ibero-Amerikanisches Institut.

Gómez, C. (1980). La comunidad campesina indigena del Loa Superior. Un enfoque etnográfico. Tesis de Licenciatura. Universidad de Chile, Santiago.

González, H. (1999). Toconce: La transformación de un sistema agro-ganadero. Estudios Atacameños, 17, 41-59.

Gudynas, E. (2013). Extracciones, extractivismos y extrahecciones. Observatorio del Desarrollo, 18. Recuperado de http://ambiental.net/wp-content/uploads/2015/12/ GudynasApropiacion ExtractivismoExtrahecciones $\mathrm{O}$ deD2013.pdf. [Consulta: 4.09.2018].

Gundermann, H. (1998). Pastoralismo andino y transformaciones sociales en el norte de Chile. Estudios Atacamenos, 16, 293-319.

Gundermann, H. (2007). Pueblos indígenas en la región atacameńa moderna. Historia Indígena, 10, 63-87.

Gundermann, H. (2013). Los atacameños y sus relaciones interétnicas. En Durston, J. (Coord.). Pueblos originarios y sociedad nacional en Chile. La interculturalidad en las prácticas sociales (pp. 80-97). Santiago: PNUD.

Gundermann, H. y Göbel, B. (2018). Comunidades indígenas, empresas del litio y sus relaciones en el Salar de Atacama. Chungara. Revista de Antropología Chilena, 50(3), 471-486.

Gundermann, H. y González, H. (1995). Tierra, agua y sociedad atacameña, un escenario cambiante. En Pourrut, P. y Núñez, L. (Eds.). Agua, ocupación del espacio y economía campesina en la región atacameña. Aspectos dinámicos (pp. 78-106). Antofagasta: UCN / Orstom.

Gundermann, H., González, H. y Durston, J. (2018). Interetnicidad y relaciones sociales en el espacio atacameño. Estudios Atacameños. Arqueología y Antropología Surandinas, 57, 161-179.
Hanson, E. (1926). Out-of-the-World Villages of Atacama. Geographical Review, 16(3), 365-377.

Hernández, R. (1974). Chiu-Chiu: la desintegración de la comunidad tradicional. Antropología. Nueva Época, 1, 17-35.

Hernández, R., Poblete, P. y Quiroz, D. (1975). Toconce: la vigencia de la comunidad tradicional. Antropología. Nueva Época, 2, 53-74.

Hodge, W. H. (1960). Yareta-Fuel Umbellifer of the Andean Puna. Economic Botany, 14(2), 113-118.

Ilustre Municipalidad de Calama (2013). Caiatunar. Semillas para una buena cosecha. Registro sociocultural de cinco semillas del Alto Loa. Calama: Ilustre Municipalidad de Calama-Departamento Andino.

Imilan, W. (2007). Socairenos en movimiento. Atacameños y Calama. Estudios Atacameños. Arqueología y Antropologia Surandinas, 33, 105-123.

Instituto Nacional de Estadísticas. (s.f.-a). Base de Datos del VI Censo Nacional Agropecuario.

Instituto Nacional de Estadísticas. (s.f.-b). Base de Datos del VII Censo Nacional Agropecuario y Forestal.

Instituto Nacional de Estadísticas. (s.f.-c). Localidades pobladas. XIV Censo Nacional de Población y III de Vivienda 1970. INE: s.i.

Instituto Nacional de Estadísticas. (1980). V Censo Nacional Agropecuario. Año Agrícola 1975-1976. Provincia de El Loa. INE: s.i.

Instituto Nacional de Estadísticas. (2018). Resultados Censo 2017. Por país, regiones y comunas. Recuperado de https:// resultados.censo2017.cl/Home/Download. [Consulta: 26.06.2018].

Kautsky, K. (1981). La cuestión agraria: análisis de las tendencias de la agricultura moderna y de la politica agraria de la socialdemocracia. México, DF: Siglo XXI.

Kay, C. (2009). Estudios rurales en América Latina en el período de globalización neoliberal: ¿una nueva ruralidad? Revista Mexicana de Sociología, 71(4), 607-645.

Kay, C. (2015). The agrarian question and the neoliberal rural transformation in Latin America. European Review of Latin American and Caribbean Studies, 100, 73-83. 
Lenin, V. (1981). El desarrollo del capitalismo en Rusia. Obras Completas. Tomo 3. Moscú: Editorial Progreso.

Levien, M., Watts, M. y Hairong, Y. (2018). Agrarian Marxism. The Jounal of Peasant Studies, 45(5-6), 853-883.

Llobera, J. (1999). La identidad de la antropología. Barcelona: Anagrama.

Lobos, J. (1957). La agricultura fuente alimenticia de la zona. Seminario de problemas regionales de Antofagasta (Universidad de Chile) (pp. 130-133). Santiago: Ediciones del Departamento de Extensión Cultural de la Universidad de Chile.

Machado, H. (2015). Crítica de la razón progresista. Una mirada marxista sobre el extractivismo/colonialismo del siglo XXI. Actuel Marx Intervenciones, 19, 137-173.

Mariátegui, J. C. (2008). 7 ensayos de interpretación de la realidad peruana. Santiago: Quimantú.

Marini, R. (2015). Dialéctica de la dependencia (1973). En América Latina, dependencia y globalización (pp. 107149). México, DF: Siglo XXI / Buenos Aires: Clacso.

Marston, A., Perreault, T. (2016). Consent, coercion and cooperativismo: Mining cooperatives and resource regimes in Bolivia. Environment and Planning A, 49(2), 252-272.

Martínez, J. (1985). La formación del actual pueblo de Toconce (siglo XIX). Chungara, 15, 99-124.

Marx, K. (1959a). "Capítulo XLVIII. La fórmula trinitaria”. "Capítulo LII. Las clases”. En El Capital Tomo III (pp. 754-769 y 817-818). México D.F.: Fondo de Cultura Económica.

Marx, K. (1959b). Capítulo XLVII. Génesis de la renta capitalista del suelo. En El Capital. Tomo III (pp. 725-753). México, DF: Fondo de Cultura Económica.

Marx, K. (1999). Capítulo XXIV. La llamada acumulación originaria. En El Capital. Tomo I (pp. 607-649). México, DF: Fondo de Cultura Económica.

Marx, K. (2003). El 18 Brumario de Luis Bonaparte. Madrid: Fundación Federico Engels.

Meneses, C. (1967). Problemas geográficos para el desarrollo de Chiu-Chiu y Lasana. Apartado del Boletín de la Asociación de geógrafos de Chile, 3, s.i.
Millán, A. (2006). La minería metálica en Chile en el siglo $X X$. Santiago: Universitaria.

Molina, F. (2012). Competing rationalities in water conflict: Mining and the indigenous community in ChiuChiu, El Loa Province, northern Chile. Singapore Journal of Tropical Geography, 33, 93-107.

Molina, R. (2019). Nostalgias, conversiones y desbordes en San Pedro de Atacama. Antropologías del Sur, 6(12), 261281.

Morales, H. y Azócar, R. (2015). Minería y relaciones interétnicas en Atacama. Estudios Atacameños. Arqueología y Antropología Surandinas, 51, 49-63.

Núñez, L. (1995). Evolución de la ocupación y organización del espacio atacameño. En Pourrut, P. y Núñez, L. (Eds.). Agua, ocupación del espacio y economía campesina en la región atacameña. Aspectos dinámicos (pp. 18-60). Antofagasta: UCN - Orstom.

Núñez, L. y Nielsen, A. (2011). Caminate, sí hay camino: reflexiones sobre el tráfico sur andino. En Núñez, L. y Nielsen, A. (Eds.). En ruta. Arqueología, historia y etnografía del tráfico sur andino (pp. 11-41). Córdoba: Encuentro Grupo Editor.

Núñez, L. y Santoro, C. (1988). Cazadores de la Puna Seca y Salada del Área Centro Sur Andina (norte de Chile). Estudios Atacameños, 9, 13-65.

Oficina de Estudios y Políticas Agrarias (s.f.). Sistema de Consulta Estadistico Territorial. Cifras Censos Agropecuarios 1997 y 2007. Recuperado de http://icet.odepa.cl/.

Parodi, M. y Benedetti, A. (2016). Minería, descampesinización y desocupación. Trayectorias de movilidad de cuatro mineros de El Aguilar (Jujuy, Argentina, década de 1940 a 2010). Estudios Atacameños. Arqueología y Antropologia Surandinas, 52, 25-48.

Pérez, C. (2008). Proposiciones de un marxismo hegeliano. Santiago: Arcis.

Perreault, T. (2013). Dispossession by accumulation? Mining, water and the nature of enclosure on the bolivian altiplano. Antipode, 45(5), 1050-1069.

Perreault, T. (Ed.). (2014). Minería, agua y justicia social en los Andes. Experiencias comparativas de Perú y Bolivia. Lima: Justicia Hídrica / La Paz: Fundación PIEB. 
Pourrut, P. y Núñez, L. (Eds.) (1995). Agua, ocupación del espacio y economía campesina en la región atacameña. Aspectos dinámicos. Antofagasta: UCN - Orstom.

Prieto, M. (2015). Privatizing Water in the Chilean Andes: The Case of Las Vegas de Chiu-Chiu. Mountain Research and Development, 35(3), 220-229.

Prieto, M. (2016a). Transando el agua, produciendo territorios e identidades indígenas: el modelo de aguas chileno y los atacameños de Calama. Revista de Estudios Sociales, $55,88-103$.

Prieto, M. (2016b). Practicing costumbres and the decommodification of nature: The Chilean water markets and the Atacameño people. Geoforum, 77, 28-39.

Risopatrón, L. (1905). El problema del Salado en la hoya del Loa. Anales Instituto de Injenieros, V(1), 1-22.

Risopatrón, L. (1918). Diario de viaje a las cordilleras de Antofagasta y Bolivia (1903-1904). Revista Chilena de Historia y Geografia, VIII-XXVII(31), 152-184.

Rivera, F. (1995). El contexto histórico y social del manejo de los recursos agropecuarios en los oasis de San Pedro de Atacama. En Pourrut, P. y Núñez, L. (Eds.). Agua, ocupación del espacio y economía campesina en la región atacameña. Aspectos dinámicos (pp. 61-77). Antofagasta: UCN - Orstom.

Rudolph, W. (1928). El Loa. Revista Chilena de Historia y Geografia, LIX(63), 66-89.

Rudolph, W. (1951). "Chuquicamata Twenty Years Later". Geographical Review, 41(1), 88-113.

Sanhueza, C. (1992). Estrategias readaptativas en Atacama: La arriería mulera colonial. En Arce, S., Barragán, R., Escobari, L. y Medinacelli, X. (Eds.). Etnicidad, economía y simbolismo en los Andes (pp. 363-385). La Paz: Hisbol - IFEA - SBH.

Sanhueza, C. (2001). Las poblaciones de la puna de Atacama y su relación con los estados nacionales. Una lectura desde el archivo. Revista de Historia Indigena, 5, 55-82.

Sanhueza, C. y Gundermann, H. (2007). Estado, expansión capitalista y sujetos sociales en Atacama (18791928). Estudios Atacameños. Arqueología y Antropología Surandinas, 34, 113-136.
Sanhueza, C. y Gundermann, H. (2009). Capitales, Estado Rentista y cambio social atacameño en las regiones interiores de Antofagasta (1879-1928). Revista Universum, 24(1), 218-246.

Sepúlveda, I., Molina, R., Delgado-Serrano, M., Guerrero, J. (2015). Agua, riego y cultivos: cambios y permanencias en los ayllus de San Pedro de Atacama. Estudios Atacameños. Arqueología y Antropología Surandinas, 51, 185-206.

Servicio Nacional de Estadística y Censos (1955). III Censo Nacional Agricola y Ganadero. Tomo I, Norte Grande y Norte Chico (Tarapacá, Antofagasta, Atacama y Coquimbo). Santiago: Servicio Nacional de Estadística y Censos.

Svampa, M. (2019). Las fronteras del neoextractivismo en América Latina. Conflictos socioambientales, giro ecoterritorial y nuevas dependencias. Edición digital. Universidad de Guadalajara - CALAS.

Veltmeyer, H. (2018). Resistance, class struggle and social movements in Latin America: contemporary dynamics. The Journal of Peasant Studies. DOI: 10.1080/03066150.2018.1493458.

Villagrán, C. y Castro, V. (1997). Etnobotánica y manejo ganadero de las vegas, bofedales y quebradas en el Loa Superior, Andes de Antofagasta, Segunda Región, Chile. Chungará, 29(2), 275-304.

Walcott, F. (1925). An Expedition to the Laguna Colorada, Southern Bolivia: With a Note on the Recent Occurrence of 'El Niño'. Geographical Review, 15(3), 345-366.

Wallerstein, I. (2003). El capitalismo historico. México, DF: Siglo XXI.

Wiedmaier, A. (1957). Monografía de la cuenca de Atacama. Seminario de problemas regionales de Antofagasta (Universidad de Chile) (pp. 146-162). Santiago: Ediciones del Departamento de Extensión Cultural, Universidad de Chile.

Wolf, E. (2005). Europa y la gente sin historia. Buenos Aires: Fondo de Cultura Económica.

Yacoub, C., Duarte, B. y Boelens, R. (Eds.). (2015). Agua y ecología politica. El extractivismo en la agroexportación, la minería y las hidroeléctricas en Latinoamérica. Quito: Abya-Yala - Justicia Hídrica. 
La cuestión agraria y el cobre en la provincia de El Loa (1929/30 - 2006/07). Andes centro-sur, norte de Chile

Yáńez, N. y Molina, R. (2008). La gran minería y los derechos indigenas en el norte de Chile. Santiago: LOM.

Yáñez, N. y Molina, R. (Comps.). (2011). Las aguas indigenas en Chile. Santiago: LOM.

(c) (1) Este es un artículo de acceso abierto bajo licencia Creative Commons Reconocimiento 4.0 Internacional 